\title{
The influence of linker geometry on uranyl complexation by rigidly- linked bis(3-hydroxy-N-methyl-pyridin-2-one)
}

\author{
Géza Szigethy, Kenneth, N. Raymond*
}

Department of Chemistry, University of California at Berkeley, Berkeley, CA, 94720-1460, USA.

Chemical Science Division, Glenn T. Seaborg Center, Lawrence Berkeley National Laboratory, Berkeley, CA, 94720, USA 


\title{
The influence of linker geometry on uranyl complexation by rigidly-linked bis(3- hydroxy-N-methyl-pyridin-2-one) ${ }^{1}$
}

Géza Szigethy, Kenneth, N. Raymond*

Department of Chemistry, University of California at Berkeley, Berkeley, CA, 94720-1460, USA. Chemical Science Division, Glenn T. Seaborg Center, Lawrence Berkeley National Laboratory, Berkeley, CA, 94720, USA

Keywords: Uranium, uranyl, HOPO, coordination geometry, crystal structure

\begin{abstract}
A series of bis(3-hydroxy-N-methyl-pyridin-2-one) ligands was synthesized and their respective uranyl complexes were characterized by single crystal X-ray diffraction analyses. These structures were inspected for high-energy conformations and evaluated using a series of metrics to measure co-planarity of chelating moieties with each other and the uranyl coordination plane, as well as to measure coordinative crowding about the uranyl dication. Both very short (ethyl, 3,4-thiophene and $o$-phenylene) and very long ( $\alpha, \alpha^{\prime}-m$-xylene and 1,8-fluorene) linkers provide optimal ligand geometries about the uranyl cation, resulting in planar, unstrained molecular arrangements. The planarity of the rigid linkers also suggests there is a degree of pre-organization for a planar coordination mode that is ideal for uranyl-selective ligand design. Comparison of intramolecular $\mathrm{N}_{\text {amide }}-\mathrm{O}_{\text {phenolate }}$ distances and ${ }^{1} \mathrm{H}$ NMR chemical shifts of amide protons supports earlier results that short linkers provide the optimal geometry for intramolecular hydrogen bonding.
\end{abstract}

\section{Introduction}

Early actinides are unique in the $f$-block of the periodic table due to their ability to adopt a wide range of oxidation states (typically $3+$ to $6+$ ), with uranium, neptunium and plutonium able to readily adopt the $5+$ or $6+$ oxidation states in oxidizing or in vivo conditions. In such high oxidation states the actinide elecrophilicity results in the formation of dioxo cations of the general formula $\mathrm{AnO}_{2}{ }^{\mathrm{n}+}(\mathrm{actinyl}$, $\mathrm{An}=\mathrm{U}, \mathrm{Np}, \mathrm{Pu} ; \mathrm{n}=1,2)^{2}$ which is linear to within a couple degrees in most of its coordination 
compounds with few exceptions..$^{3-5}$ While the oxo atoms in $\mathrm{AnO}_{2}{ }^{+}$cations $[\mathrm{An}(\mathrm{V})]$ exhibit some Lewis basic behavior ${ }^{6-9}$ similar to transition metal oxo species, the oxo atoms in $\mathrm{AnO}_{2}{ }^{2+}$ cations $[\mathrm{An}(\mathrm{VI})]$ display poor Lewis basicity and are typically only observed to interact with Lewis acids when in the solid state and in carefully designed coordination environments. ${ }^{10-14}$ Furthermore, the non-spherical geometry of actinyl cations makes them particularly problematic for polyaminoacetic acid-based chelation therapies due to the incomplete utilization of the spherically-arranged chelating atoms therein. ${ }^{15}$ The resultant low association constants and in vivo affinity for actinyl cations emphasizes the need for high-efficiency, actinyl-selective chelation agents for decontamination applications of both biological and environmental systems.

Most actinyl chelation efforts have focused on the uranyl cation $\left(\mathrm{UO}_{2}{ }^{2+}\right)$ because uranium is a naturally-occurring actinide element and is the primary source of nuclear fuel for civilian and military applications. ${ }^{16}$ Design strategies for actinyl specific ligands must differ from those for spherical ions to enable ligand coordination only in an equatorial plane perpendicular to the $\mathrm{O}=\mathrm{An}=\mathrm{O}$ vectors. The equatorial coordination plane displays little to no orbital-dictated directionality, with observed coordination geometries ranging from trigonal- through hexagonal-planar, depending on ligand sterics and chelating ability. ${ }^{12,17-19}$ While previous uranyl chelation efforts in our laboratory have attempted to employ ligand-directed Lewis acid/base interactions with the terminal oxo atoms, ${ }^{20,21}$ recent work has explored the more classical equatorial coordination behavior of the uranyl cation with tetradentate bis(3hydroxy-N-methyl-pyridin-2-one) (bis-Me-3,2-HOPO) ligands. ${ }^{22,23}$ Linearly-linked nLi-Me-3,2-HOPO ligands (where "Li" stands for "linear" and "n" represents the number of methylene units in the linker) bind at four points of a pentagonal-planar coordination geometry about the uranyl cation, with the fifth position occupied by solvent. ${ }^{23}$ This behavior is similar to the geometry observed with the unconstrained, propyl-substituted bidentate Pr-Me-3,2-HOPO moiety ${ }^{23}$ and is also observed with other 
bidentate ligands of similar bite angle (e.g. 3-hydroxy-pyran-4-ones, 1,2-HOPO, tropolonate). ${ }^{24-26}{ }^{1} \mathrm{H}$ NMR studies revealed that short linkers (e.g. 2Li-) optimize an intramolecular hydrogen bond responsible for stabilizing the deprotonated and metal-chelated forms of Me-3,2-HOPO and catecholamide ligands; ${ }^{27}$ rigidifying this geometry using the 3,4-thiophene linker resulted in the most planar coordination mode about the uranyl cation yet observed with this ligand class. ${ }^{22}$

Our focus here is to expand the known coordination behavior of bis-Me-3,2-HOPO ligands with the uranyl cation by utilizing a variety of rigid linkers and examining the crystal structures of their uranyl complexes. Therefore, a series of bis-Me-3,2-HOPO ligands containing aromatic linkers were designed, synthesized and their $\mathrm{UO}_{2}$ complexes crystallized (Figure 1). The linkers were chosen to provide diverse ligand geometries and degrees of rigidity via the ring size/substitution and absence/presence of flexible methylene spacers, respectively. Similar to "nLi-" notation, the number of carbon atoms between the amide nitrogens (hereon referred to as $n$ ) was varied between 2 and 5, providing a similar ligand size scope to that explored previously. ${ }^{23}$ The 1,8-fluorene linker in $\mathbf{L}^{12} \mathbf{H}_{2}$ was included because conformational analysis by the program HostDesigner ${ }^{28,29}$ suggested it would provide a coordination geometry similar to that seen with $4 \mathrm{Li}-\mathrm{Me}-3,2-\mathrm{HOPO}$, which itself has been shown to approach the unconstrained uranyl chelation geometry observed using $\operatorname{Pr}-\mathrm{Me}-3,2-\mathrm{HOPO}{ }^{23}$ 

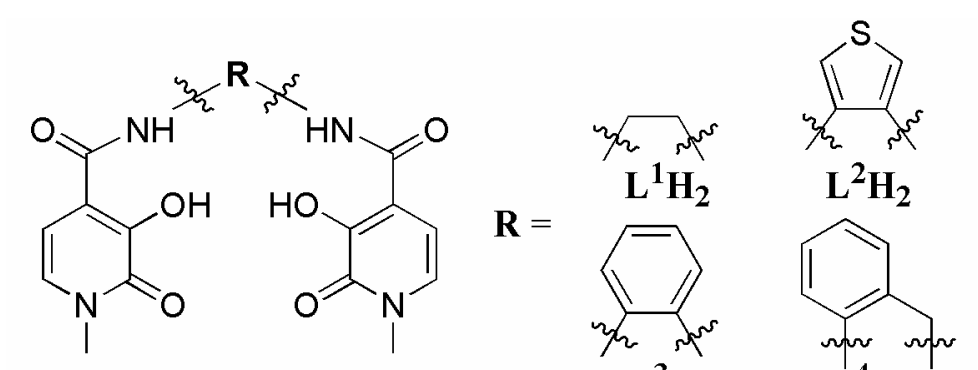

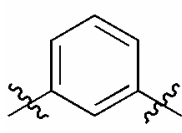

$\mathrm{L}^{5} \mathrm{H}_{2}$<smiles>CCc1cccc(CC)c1</smiles>

$\mathrm{L}^{9} \mathrm{H}_{2}$<smiles>[Y]c1cccc(C)n1</smiles>

$\mathbf{L}^{6} \mathrm{H}_{2}$<smiles>Cc1cccc2cccc(O)c12</smiles>

$\mathbf{L}^{3} \mathrm{H}_{2}$

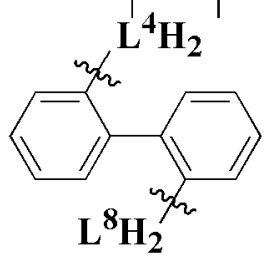

Figure 1. Bis-Me-3,2-HOPO ligands explored in this study.

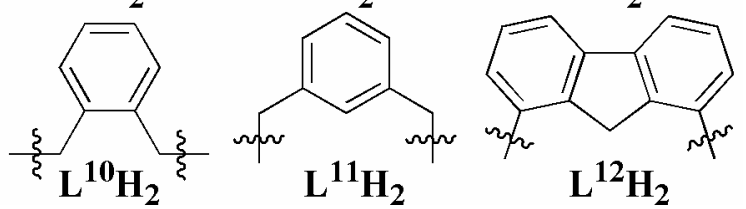

The differences between the ligand geometries in Figure 1 range from subtle angular differences in backbone attachments [3,4-thiophene-Me-3,2-HOPO $\left(\mathbf{L}^{2} \mathbf{H}_{\mathbf{2}}\right)$ versus o-phenylene-Me-3,2-HOPO $\left.\left(\mathbf{L}^{3} \mathbf{H}_{2}\right)\right]$ to large differences in backbone flexibility [ $\alpha, \alpha^{\prime}-m$-xylene-Me-3,2-HOPO $\left(\mathbf{L}^{11} \mathbf{H}_{2}\right)$ versus 1,8fluorene-Me-3,2-HOPO $\left.\left(\mathbf{L}^{12} \mathbf{H}_{2}\right)\right]$. Between $m$-phenylene-Me-3,2-HOPO $\left(\mathbf{L}^{5} \mathbf{H}_{\mathbf{2}}\right)$ and 2,6-pyridine-Me3,2-HOPO $\left(\mathbf{L}^{6} \mathbf{H}_{2}\right)$ the only difference is the introduction of the pyridine nitrogen, which was expected to act as a hydrogen bond acceptor in the uranyl complex. Ligand $\mathbf{L}^{1} \mathbf{H}_{\mathbf{2}}$ was previously synthesized ${ }^{23}$ but is included in the current study to provide structural characterization of its uranyl complex. The uranyl complex with $\mathbf{L}^{2} \mathbf{H}_{2}$ is also discussed elsewhere, ${ }^{22}$ but along with ligand $\mathbf{L}^{1} \mathbf{H}_{\mathbf{2}}$ and $\mathbf{L}^{3} \mathbf{H}_{\mathbf{2}}$, utilizes one of the shortest linkers of this study and provides important comparisons with the linkers of larger $n$ values.

\section{Experimental Section}

General Information. Unless otherwise noted, all chemicals and solvents were purchased from commercial sources and used as received. All reactions brought to reflux were done so with an efficient condenser attached to the reaction flask. NMR spectra were collected using Bruker AMX-400 and AM- 
400 spectrometers $\left({ }^{1} \mathrm{H} 400 \mathrm{MHz},{ }^{13} \mathrm{C} 100 \mathrm{MHz}\right.$ ). ${ }^{1} \mathrm{H}$ (or ${ }^{13} \mathrm{C}$ ) NMR resonances are reported in ppm relative to the solvent resonances, taken as 2.50 (39.51) for DMSO- $d_{6}$. Mass spectrometry and elemental analyses were performed at the Microanalytical Facility, College of Chemistry, University of California, Berkeley. Yields indicate the amount of isolated compound and reactions are un-optimized.

Synthesis/Crystallization Techniques for Uranyl complexes: Unless otherwise stated, one equivalent of bis-Me-3,2-HOPO ligand was suspended in $10 \mathrm{~mL}$ of $\mathrm{MeOH}$ and two equivalents of methanolic $\mathrm{KOH}(0.5051 \mathrm{M}$, Aldrich) was added. The suspension was stirred for three minutes, in most cases becoming a homogeneous solution. This ligand solution was added to a stirred solution of 1-1.2 equivalents of $\mathrm{UO}_{2}\left(\mathrm{NO}_{3}\right)_{2} \cdot 6 \mathrm{H}_{2} \mathrm{O}$ in $4 \mathrm{~mL}$ of $\mathrm{MeOH}$. The resulting reddish suspension was brought to reflux and allowed to stir overnight. The solution was cooled, filtered and washed with $\mathrm{MeOH}$. The solid was dried under vacuum to remove residual $\mathrm{MeOH}$ and then exposed to atmosphere until the sample mass stabilized.

$\mathrm{UO}_{2}(\mathbf{2} \mathrm{Li}-\mathrm{Me}-\mathbf{3}, \mathbf{2}-\mathrm{HOPO}), \mathrm{UO}_{2}\left(\mathbf{L}^{1}\right)$. Synthesis of this complex is described in the literature. ${ }^{23} \mathrm{In}$ order to grow X-ray quality crystals, $\mathbf{L}^{1} \mathbf{H}_{\mathbf{2}}(68 \mathrm{mg}, 0.19 \mathrm{mmol})$ was dissolved in $10 \mathrm{~mL}$ of DMF with 15 drops of $\mathrm{Et}_{3} \mathrm{~N}$. This blue solution was added to a stirred solution of $\mathrm{UO}_{2}\left(\mathrm{NO}_{3}\right)_{2} \cdot 6 \mathrm{H}_{2} \mathrm{O}(86 \mathrm{mg}, 0.17$ mmol) in $2 \mathrm{~mL}$ of DMF. After a short-lived precipitate re-dissolved, the red solution was stirred at room temperature overnight, followed by removal of the solvent under vacuum. The residue was stirred in 1 $\mathrm{mL}$ of 1:1 DMF:DMSO and insoluble material was removed by filtration through a small plug of celite. Diffusion of $\mathrm{MeOH}$ into this solution at room temperature yielded very small, X-ray quality crystals.

$\mathbf{U O}_{2}\left(\boldsymbol{o}\right.$-phenylene-Me-3,2-HOPO), $\mathbf{U O}_{2}\left(\mathbf{L}^{3}\right)$. The $\mathrm{UO}_{2}\left(\mathbf{L}^{3}\right)(\mathrm{DMSO})$ complex was isolated by diffusing $\mathrm{Et}_{2} \mathrm{O}$ into a filtered solution of $\mathbf{L}^{3} \mathbf{H}_{2}(21.2 \mathrm{mg}, 0.0515 \mathrm{mmol}), \mathrm{UO}_{2}\left(\mathrm{NO}_{3}\right)_{2} \cdot 6 \mathrm{H}_{2} \mathrm{O}(26.7 \mathrm{mg}$, $0.0531 \mathrm{mmol}$ ) and two drops of $\mathrm{Et}_{3} \mathrm{~N}$ in $4 \mathrm{~mL}$ of DMF and $2 \mathrm{~mL}$ of DMSO, yielding a crop of red crystals, $23 \mathrm{mg}(59 \%)$. These crystals were used for single crystal X-ray diffraction characterization. 
Anal. Calcd (Found) for $\mathrm{C}_{20} \mathrm{H}_{16} \mathrm{~N}_{4} \mathrm{O}_{8} \mathrm{U} \cdot \mathrm{C}_{2} \mathrm{H}_{6} \mathrm{OS}$ (\%): C, 34.93 (34.62); H, 2.93 (2.68); N, 7.41 (7.07); $\mathrm{S}$, 4.24 (4.30). ${ }^{1} \mathrm{H}$ NMR (DMSO- $\left.d_{6}\right): \delta 2.54\left(\mathrm{~s}, 6 \mathrm{H}, \mathrm{DMSO} \mathrm{CH}_{3}\right), 3.99$ (s, 6H, $\left.\mathrm{CH}_{3}\right), 7.18-7.20(\mathrm{~m}, 4 \mathrm{H}$, arom. $H+\mathrm{HOPO} H), 7.32(\mathrm{~d}, 2 \mathrm{H}, J=6.4 \mathrm{~Hz}$, HOPO $H$ ), $8.74(\mathrm{dd}, 2 \mathrm{H}, J=6.4,4.0 \mathrm{~Hz}$, arom. $H), 12.38$ (s, $2 \mathrm{H}, \mathrm{N} H$ ). ${ }^{13} \mathrm{C}$ NMR (DMSO- $\left.d_{6}\right): \delta 40.42,110.38,120.54,122.07,123.82,124.82,128.18,158.84$, 162.87, 167.65. MS (FAB+): m/z $679(\mathrm{MH}+)$.

$\mathbf{U O}_{2}\left(\boldsymbol{o}\right.$-toluene-Me-3,2-HOPO), $\mathbf{U O}_{2}\left(\mathbf{L}^{4}\right)$. The $\mathrm{UO}_{2}\left(\mathbf{L}^{4}\right)(\mathrm{DMSO})$ complex was crystallized by diffusing $\mathrm{MeOH}$ at room temperature into a solution of $\mathbf{L}^{4} \mathbf{H}_{2} \cdot 3 / 4 \mathrm{H}_{2} \mathrm{O}(16.5 \mathrm{mg}, 0.0377 \mathrm{mmol})$, $\mathrm{UO}_{2}\left(\mathrm{NO}_{3}\right)_{2} \cdot 6 \mathrm{H}_{2} \mathrm{O}(20.9 \mathrm{mg}, 0.0416 \mathrm{mmol})$ and three drops of $\mathrm{Et}_{3} \mathrm{~N}$ in $1 / 2 \mathrm{~mL}$ of DMSO, yielding $23 \mathrm{mg}$ of a dark red crystalline solid which analysis revealed to be the monohydrate, $77 \%$. Crystals suitable for X-ray diffraction were isolated in a similar manner but from a different batch of uranyl complex. Anal. Calcd (Found) for $\mathrm{C}_{21} \mathrm{H}_{18} \mathrm{~N}_{4} \mathrm{O}_{8} \mathrm{U} \cdot \mathrm{C}_{2} \mathrm{H}_{6} \mathrm{OS} \cdot \mathrm{H}_{2} \mathrm{O}$ (\%): C, 35.03 (34.68); H, 3.32 (3.08); N, 7.10 (6.87); $\mathrm{S}$, 4.07 (4.32). ${ }^{1} \mathrm{H}$ NMR (DMSO-d $\left.d_{6}\right): \delta 2.54$ (s, $6 \mathrm{H}, \mathrm{DMSO} H$ ), 3.94 (s, 3H, $\left.\mathrm{CH}_{3}\right), 4.00$ (s, 3H, $\left.\mathrm{CH}_{3}\right), 4.65$ (br,s, 2H, $\mathrm{CH}_{2}$ ), $7.03(\mathrm{~d}, 1 \mathrm{H}, J=7.2 \mathrm{~Hz}, \mathrm{HOPO} H$ ), 7.21-7.26 (m, 3H, HOPO $H+$ arom. $H$ ), 7.31-7.36 (m, 2H, HOPO $H+$ arom. $H), 7.54(\mathrm{dd}, 1 \mathrm{H}, J=7.6,1.2 \mathrm{~Hz}$, arom. $H), 7.68(\mathrm{~d}, 1 \mathrm{H}, J=7.6 \mathrm{~Hz}$, arom. $H$ ), $11.40(\mathrm{t}, 1 \mathrm{H}, J=6.8 \mathrm{~Hz}, \mathrm{~N} H), 11.62(\mathrm{~s}, 1 \mathrm{H}, \mathrm{N} H) .{ }^{13} \mathrm{C}$ NMR (DMSO-d $\left.d_{6}\right): \delta 37.46,37.74,40.42,109.84$, $110.86,120.57,120.98,124.07,124.93,125.48,126.81,127.98,131.47,132.51,136.79 . \mathrm{MS}(\mathrm{FAB}+)$ : $\mathrm{m} / \mathrm{z} 693(\mathrm{MH}+)$.

$\mathbf{U O}_{2}\left(\boldsymbol{m}\right.$-toluene-Me-3,2-HOPO), $\mathbf{U O}_{2}\left(\mathbf{L}^{9}\right)$. Red powder isolated as the dihydrate, $92 \%$. Anal. Calcd (Found) for $\mathrm{C}_{21} \mathrm{H}_{18} \mathrm{~N}_{4} \mathrm{O}_{8} \mathrm{U} \cdot 2 \mathrm{H}_{2} \mathrm{O}$ (\%): C, 34.62 (34.56); H, 3.04 (2.88); N, 7.69 (7.55). ${ }^{1} \mathrm{H}$ NMR (DMSO- $d_{6}$ ): $\delta 3.97$ (s, $3 \mathrm{H}, \mathrm{CH}_{3}$ ), $3.98\left(\mathrm{~s}, 3 \mathrm{H}, \mathrm{CH}_{3}\right), 4.56\left(\mathrm{~d}, 2 \mathrm{H}, J=6.0 \mathrm{~Hz}, \mathrm{CH}_{2}\right), 6.64(\mathrm{~d}, 1 \mathrm{H}, J=6.8$ Hz, HOPO $H$ ), $7.03(\mathrm{~d}, 1 \mathrm{H}, J=7.6 \mathrm{~Hz}$, arom. $H$ ), $7.10(\mathrm{~d}, 1 \mathrm{H}, J=7.2 \mathrm{~Hz}, \mathrm{HOPO} H), 7.21(\mathrm{~d}, 1 \mathrm{H}, J=$ $6.8 \mathrm{~Hz}, \mathrm{HOPO} H), 7.32(\mathrm{~d}, 1 \mathrm{H}, J=7.2 \mathrm{~Hz}, \mathrm{HOPO} H), 7.38(\mathrm{t}, 1 \mathrm{H}, J=7.6 \mathrm{~Hz}$, arom. $H$ ), $7.99(\mathrm{~s}, 1 \mathrm{H}$, arom. $H), 8.21(\mathrm{~d}, 1 \mathrm{H}, J=8.0 \mathrm{~Hz}$, arom. $H), 9.14(\mathrm{t}, 1 \mathrm{H}, J=6.0 \mathrm{~Hz}, \mathrm{~N} H), 13.35(\mathrm{~s}, 1 \mathrm{H}, \mathrm{N} H) .{ }^{13} \mathrm{C} \mathrm{NMR}$ 
(DMSO- $\left.d_{6}\right): \delta 37.61,37.67,41.05,109.21,111.43,115.25,117.04,120.87,121.18,123.98,124.95$, $128.39,129.30,139.17,139.85,157.07,160.38,161.73,166.68,168.31,168.36$. MS (FAB+): m/z 693 $(\mathrm{MH}+)$. X-ray quality crystals were grown by diffusing $\mathrm{MeOH}$ into a 1:1 DMF:DMSO solution of this material at $4{ }^{\circ} \mathrm{C}$.

$\mathbf{U O}_{2}\left(\boldsymbol{\alpha}, \boldsymbol{\alpha}^{\prime}\right.$-o-xylene-Me-3,2-HOPO$), \mathbf{U O}_{2}\left(\mathbf{L}^{10}\right)$. A solution of $\mathbf{L}^{10} \mathbf{H}_{2} \cdot 1.5 \mathrm{H}_{2} \mathrm{O}(22 \mathrm{mg}, 0.047 \mathrm{mmol})$ in $4 \mathrm{~mL}$ of 1:1 DMF:DMSO and four drops of $\mathrm{Et}_{3} \mathrm{~N}$ was added to a stirred solution of $\mathrm{UO}_{2}\left(\mathrm{NO}_{3}\right)_{2} \cdot 6 \mathrm{H}_{2} \mathrm{O}$ (27 mg, $0.053 \mathrm{mmol}$ ) in $2 \mathrm{~mL}$ of DMF. The red solution was stirred for ten minutes and then $\mathrm{MeOH}$ was diffused into the solution at room temperature, resulting in a crop of red crystals. These were filtered, washed with $\mathrm{MeOH}$ and dried by aspiration to give the $\mathrm{UO}_{2}\left(\mathbf{L}^{10}\right) \cdot \mathrm{H}_{2} \mathrm{O} \cdot \mathrm{CH}_{3} \mathrm{OH}$ in quantitative yields. Anal. Calcd (Found) for $\mathrm{C}_{22} \mathrm{H}_{20} \mathrm{~N}_{4} \mathrm{O}_{8} \mathrm{U} \cdot \mathrm{H}_{2} \mathrm{O} \cdot \mathrm{CH}_{3} \mathrm{OH}(\%)$ : C, 36.52 (36.56); H, 3.46 (3.37); N, 7.41 (7.09). ${ }^{1} \mathrm{H}$ NMR (DMSO- $\left.d_{6}\right): \delta 3.17\left(\mathrm{~d}, 3 \mathrm{H}, J=5.2 \mathrm{~Hz}, \mathrm{CH}_{3} \mathrm{OH}\right), 3.95\left(\mathrm{~s}, 6 \mathrm{H}, \mathrm{CH}_{3}\right), 4.11(\mathrm{q}, 1 \mathrm{H}, J$ $\left.=5.2 \mathrm{~Hz}, \mathrm{CH}_{3} \mathrm{OH}\right), 4.95\left(\mathrm{~d}, 4 \mathrm{H}, J=6.0 \mathrm{~Hz}, \mathrm{CH}_{2}\right), 7.18(\mathrm{~d}, 2 \mathrm{H}, J=7.2 \mathrm{~Hz}, \mathrm{HOPO} H), 7.27-7.29(\mathrm{~m}, 4 \mathrm{H}$, HOPO $H+$ arom. $H), 7.51(\mathrm{dd}, 2 \mathrm{H}, J=5.6,3.6 \mathrm{~Hz}$, arom. $H), 10.12(\mathrm{t}, 2 \mathrm{H}, J=6.0 \mathrm{~Hz}, \mathrm{~N} H) .{ }^{13} \mathrm{C} \mathrm{NMR}$ (DMSO- $\left.d_{6}\right): \delta 37.71,38.23,48.61,110.75,121.06,124.26,128.40,131.22,138.06,159.84,163.59$, 168.39. $\mathrm{MS}(\mathrm{FAB}+): \mathrm{m} / \mathrm{z} 707(\mathrm{MH}+)$. X-ray quality crystals were grown following a similar procedure, although from a different batch as that described here.

$\mathbf{U O}_{2}\left(\boldsymbol{\alpha}, \boldsymbol{\alpha}^{\prime}-\boldsymbol{m}\right.$-xylene-Me-3,2-HOPO), $\mathbf{U O}_{2}\left(\mathbf{L}^{11}\right)$. Red/orange solid isolated as the trihydrate, $80 \%$. Anal. Calcd (Found) for $\mathrm{C}_{22} \mathrm{H}_{20} \mathrm{~N}_{4} \mathrm{O}_{8} \mathrm{U} \cdot 3 \mathrm{H}_{2} \mathrm{O}$ (\%): C, 34.75 (34.90); H, 3.45 (3.12); N, 7.37 (7.18). ${ }^{1} \mathrm{H}$ NMR (DMSO- $\left.d_{6}\right): \delta 3.97\left(\mathrm{~s}, 6 \mathrm{H}, \mathrm{CH}_{3}\right), 4.71\left(\mathrm{~d}, 4 \mathrm{H}, J=5.2 \mathrm{~Hz}, \mathrm{CH}_{2}\right), 7.12(\mathrm{~d}, 2 \mathrm{H}, J=7.2 \mathrm{~Hz}, \mathrm{HOPO}$ $H$ ), $7.28(\mathrm{~d}, 2 \mathrm{H}, J=7.2 \mathrm{~Hz}, \mathrm{HOPO} H), 7.37$ (s, 3H, arom. $H$ ), 7.95 (s, $1 \mathrm{H}$, arom. $H$ ), $9.46(\mathrm{t}, 2 \mathrm{H}, J=5.2$ $\mathrm{Hz}, \mathrm{N} H) .{ }^{13} \mathrm{C}$ NMR (DMSO- $\left.d_{6}\right): \delta 37.71,43.07,110.69,121.52,124.09,125.98,127.29,128.99$, 139.05, 160.18, 163.69, 168.25. MS $(\mathrm{FAB}+): \mathrm{m} / \mathrm{z} 689$ [(M-O)+]. X-ray quality crystals of $\mathrm{UO}_{2}(\mathbf{1 1})(\mathrm{DMF})$ were grown by diffusing $\mathrm{MeOH}$ into a DMF solution of the compound at $4{ }^{\circ} \mathrm{C}$. 
UO $\mathbf{O}_{2}\left(\mathbf{1 , 8}\right.$-fluorene-Me-3,2-HOPO), $\mathbf{U O}_{2}\left(\mathbf{L}^{\mathbf{1 2}}\right)$. A solution of $\mathbf{L}^{12} \mathbf{H}_{2} \cdot 1 / 2 \mathrm{H}_{2} \mathrm{O}(34 \mathrm{mg}, 0.063 \mathrm{mmol})$ in 4 $\mathrm{mL}$ of DMF and 3 drops of $\mathrm{Et}_{3} \mathrm{~N}$ was added to a solution of $\mathrm{UO}_{2}\left(\mathrm{NO}_{3}\right)_{2} \cdot 6 \mathrm{H}_{2} \mathrm{O}(35 \mathrm{mg}, 0.070 \mathrm{mmol})$ in 2 $\mathrm{mL}$ of DMF. The red solution quickly became turbid, and after stirring overnight at room temperature, the DMF was removed under vacuum. The residue was suspended in $\mathrm{MeOH}$, filtered, washed with $\mathrm{MeOH}$, and dried by aspiration, yielding $50 \mathrm{mg}$ of an orange solid as the $\mathrm{UO}_{2}\left(\mathbf{L}^{\mathbf{1 2}}\right) \cdot \mathrm{DMF} \cdot 2 \mathrm{H}_{2} \mathrm{O}$ adduct, 83\%. Anal. Calcd (Found) for $\mathrm{C}_{27} \mathrm{H}_{20} \mathrm{~N}_{4} \mathrm{O}_{8} \mathrm{U} \cdot \mathrm{DMF} \cdot 2 \mathrm{H}_{2} \mathrm{O}$ (\%): C, 41.15 (41.33); H, 3.57 (3.39); N, 8.00 (7.67). This isolated solid was too insoluble in DMSO for NMR analysis. MS (FAB+): m/z $767(\mathrm{MH}+)$. A small crop of X-ray quality crystals were grown by slow cooling of a near-boiling reaction mixture of $\mathbf{L}^{12} \mathbf{H}_{2} \cdot 1 / 2 \mathrm{H}_{2} \mathrm{O}(23 \mathrm{mg}, 0.046 \mathrm{mmol}), \mathrm{UO}_{2}\left(\mathrm{NO}_{3}\right)_{2} \cdot 6 \mathrm{H}_{2} \mathrm{O}(27 \mathrm{mg}, 0.054 \mathrm{mmol})$ and two drops of $\mathrm{Et}_{3} \mathrm{~N}$ in 6 mL of DMSO.

X-ray Diffraction Data Collection/Refinement: Uranyl complex crystals were mounted on captan loops with oil and cooled under a controlled temperature stream of liquid nitrogen boil-off during data collection. X-ray diffraction data were collected at the UC Berkeley X-ray crystallographic facility, using either Bruker SMART 1000 or APEX I detectors with Mo $\mathrm{K}_{\alpha}$ radiation, or at Endstation 11.3.1 at the Advanced Light Source (ALS) at LBNL, using a Bruker Platinum 200 or APEX II detector with synchrotron radiation $(\mathrm{hv}=16 \mathrm{keV})$. All data were integrated by the program SAINT. ${ }^{30,31}$ The data were corrected for Lorentz and polarization effects. Data were analyzed for agreement and possible absorption using XPREP and an empirical absorption correction was applied in SADABS. ${ }^{32,33}$ Equivalent reflections were merged without an applied decay correction. All structures were solved using direct methods and were expanded with Fourier techniques using the SHELXL package. ${ }^{34}$ Convergence was reached by repeated least squares refinement on $\mathrm{F}^{2}$ against all reflections. Least squares planes and angles between them were calculated using the SHELXL package. ${ }^{34}$ Further details on the crystallographic refinement of the crystal structures are provided in the Supporting Information. 


\section{Results and Discussion}

Synthesis of uranyl complexes. Most uranyl complexes with bis-Me-3,2-HOPO ligands could be isolated following one of two general procedures. The first method consisted of refluxing the bis-Me3,2-HOPO ligand with uranyl nitrate and $\mathrm{Et}_{3} \mathrm{~N}$ or methanolic $\mathrm{KOH}$ as base, resulting in the precipitation of an orange or red powder which could be filtered. These powders were dried under vacuum over $\mathrm{P}_{2} \mathrm{O}_{5}$, but because the uranyl complexes are typically hygroscopic, their solids were often isolated as their polysolvates following this method. The second method involved dissolving the bis-Me-3,2-HOPO ligand, uranyl nitrate, and $\mathrm{Et}_{3} \mathrm{~N}$ in $\mathrm{DMF}$ or $\mathrm{DMSO}$, making a dark red, homogeneous solution of the uranyl complex. Diffusion of a volatile organic solvent into this solution at room temperature or $4{ }^{\circ} \mathrm{C}$ yielded the uranyl complexes in their crystalline form, which were isolated by filtration and dried by aspiration overnight, often leading to solvates of the uranyl complexes. This latter procedure also describes the crystallization procedures for uranyl complexes isolated via precipitation. The highly insoluble $\mathrm{UO}_{2}\left(\mathbf{L}^{\mathbf{1 2}}\right)$ complex could only be crystallized by slow cooling of a near-boiling DMSO solution, resulting in crystal formation only above ca. $140{ }^{\circ} \mathrm{C}$, with polycrystalline or amorphous materials quickly precipitating at lower temperatures.

The uranyl complexes ranged in color from orange to red, and in some cases brown $\left[\mathrm{UO}_{2}\left(\mathbf{L}^{2}\right)\right]$, but their hue is observed to be solvent-dependent, with the complexes typically dark red in the presence of DMSO or DMF, and lighter red or orange in the presence of water or methanol. It is known from previous work with $\mathrm{UO}_{2}$ (bis-Me-3,2-HOPO) complexes that the uranyl coordination plane is not saturated by the bis-Me-3,2-HOPO ligands, ${ }^{22,23}$ and so this color change is most assuredly caused by variable coordination at the fifth equatorial position, modifying the ligand-to-metal charge-transfer transition energy. This behavior also explains the general inability to isolate the uranyl complex free of 
solvent, whether in a crystalline or amorphous phase. Because the uranyl center must coordinate a fifth atom to achieve coordinative saturation with bis-Me-3,2-HOPO ligands, the solvent system was of utmost importance in crystallization processes, with DMSO generally yielding the most reproducible products. As a result of this coordinative variability, crystal color ranged from orange to deep red, with solvent inclusions common in the crystal lattice.

While uranyl complexation reactions with most ligands depicted in Figure 1 led to the formation of $\mathrm{UO}_{2} \mathrm{~L}$ (solv.) complexes (where $\mathrm{L}$ is the tetradentate, bis-Me-3,2-HOPO ligand), reactions with ligands $\mathbf{L}^{5} \mathbf{H}_{2}$ through $\mathbf{L}^{8} \mathbf{H}_{2}$ led only to precipitation of intractable red or orange solids, a result that was independent of reaction concentration, solvent, and temperature $\left(25-140{ }^{\circ} \mathrm{C}\right)$. Their intractable nature (low solubility even in hot DMSO) made their characterization by NMR or mass spectrometry difficult, although MALDI mass spectrometry was suggestive of polymer formation. Coordination polymer formation with these ligands can be rationalized by closer inspection of their ligand geometries. In ligands $\mathbf{L}^{5} \mathbf{H}_{2}, \mathbf{L}^{6} \mathbf{H}_{2}$ and $\mathbf{L}^{7} \mathbf{H}_{2}$, the linkers are completely rigid species, providing very little flexibility to the ligand; ligands $\mathbf{L}^{5} \mathbf{H}_{\mathbf{2}}$ and $\mathbf{L}^{6} \mathbf{H}_{\mathbf{2}}$ hold the HOPO moieties far away from each other while $\mathbf{L}^{7} \mathbf{H}_{\mathbf{2}}$ holds them very close. In such instances, the ligands are apparently incapable of distorting enough to enable mononuclear species formation and must each bind to more than one uranyl cation, leading to a polymeric mixture of products. Although ligand $\mathbf{L}^{8} \mathbf{H}_{2}$ contains some degree of rotational freedom about its central bond, it too, is apparently more inclined to bind two independent uranyl cations rather than one, again resulting in polymer formation. Thus, the linker geometries of $\mathbf{L}^{5} \mathbf{H}_{2}$ through $\mathbf{L}^{8} \mathbf{H}_{2}$ serve to define the effective limits of mononuclear bis-Me-3,2-HOPO ligand chelating capacity with the uranyl cation.

X-ray diffraction analysis of uranyl complexes. Crystalline uranyl complexes with ligands $\mathbf{L}^{1}-\mathbf{L}^{4}$ and $\mathbf{L}^{9}-\mathbf{L}^{12}$ exhibited a variety of crystal habits ranging from blocks to needles to thin plates. Due to 
their small size and poor diffraction, high intensity synchrotron radiation was occasionally required to collect data sufficient for crystallographic characterizations. These measurements were performed at Endstation 11.3.1 of the Advanced Light Source at Lawrence Berkeley National Laboratory. Crystal structures of the $\mathrm{UO}_{2}$ (bis-Me-3,2-HOPO) complexes with $\mathbf{L}^{1}, \mathbf{L}^{3}, \mathbf{L}^{4}$, and $\mathbf{L}^{9}$ through $\mathbf{L}^{12}$ are shown in Figure 2 and their crystallographic parameters are listed in Table 1.

Table 1. Crystallographic information for novel $\mathrm{UO}_{2}$ (bis-Me-3,2-HOPO) complexes.

\begin{tabular}{|c|c|c|c|c|c|c|c|}
\hline Compound & $\mathrm{UO}_{2}\left(\mathbf{L}^{1}\right)$ & $\mathrm{UO}_{2}\left(\mathbf{L}^{3}\right)(\mathrm{DMSO})$ & $\mathrm{UO}_{2}\left(\mathbf{L}^{4}\right)(\mathrm{DMSO})$ & $\mathrm{UO}_{2}\left(\mathrm{~L}^{9}\right)(\mathrm{MeOH})$ & $\mathrm{UO}_{2}\left(\mathrm{~L}^{10}\right)$ & $\mathbf{U O}_{2}\left(\mathrm{~L}^{11}\right)(\mathrm{DMF})$ & $\mathrm{UO}_{2}\left(\mathrm{~L}^{12}\right)(\mathrm{DMSO})$ \\
\hline Formula & $\mathrm{C}_{18} \mathrm{H}_{16} \mathrm{~N}_{4} \mathrm{O}_{8} \mathrm{U}$ & $\mathrm{C}_{22} \mathrm{H}_{22} \mathrm{~N}_{4} \mathrm{O}_{9} \mathrm{SU}$ & $\mathrm{C}_{23} \mathrm{H}_{24} \mathrm{~N}_{4} \mathrm{O}_{9} \mathrm{SU}$ & $\begin{array}{l}\mathrm{C}_{22} \mathrm{H}_{22} \mathrm{~N}_{4} \mathrm{O}_{9} \mathrm{U} \\
\mathrm{C}_{2} \mathrm{H}_{6} \mathrm{OS}\end{array}$ & $\begin{array}{l}\mathrm{C}_{22} \mathrm{H}_{20} \mathrm{~N}_{4} \mathrm{O}_{8} \\
\mathrm{U} \cdot \\
\mathrm{CH}_{4} \mathrm{O}\end{array}$ & $\mathrm{C}_{25} \mathrm{H}_{27} \mathrm{~N}_{5} \mathrm{O}_{9} \mathrm{U}$ & $\begin{array}{l}\mathrm{C}_{29} \mathrm{H}_{26} \mathrm{~N}_{4} \mathrm{O}_{9} \mathrm{SU} \cdot \\
1.6 \mathrm{H}_{2} \mathrm{O}\end{array}$ \\
\hline MW & 630.36 & 756.53 & 770.55 & 802.59 & 738.49 & 779.55 & 870.15 \\
\hline $\mathrm{T}[\mathrm{K}]$ & $223(2)$ & 161(2) & 193(2) & $165(2)$ & $155(2)$ & $180(2)$ & $173(2)$ \\
\hline Cryst. system & Monoclinic & Monoclinic & Triclinic & Triclinic & Monoclinic & Triclinic & Orthorhombic \\
\hline Space group & $P 2_{1} / c$ & $P 2_{1} / n$ & $P-1$ & $P-1$ & $P 2_{1} / c$ & $P-1$ & Pnma \\
\hline Appearance & Plate & Prism & Plate & Wedge & Prism & Plate & Rhombohedron \\
\hline Color & Red & Red & Red & Orange & Red & Red & Red \\
\hline$a[\AA]$ & $8.282(2)$ & $13.7333(7)$ & $7.0126(5)$ & $8.8897(18)$ & $9.0217(5)$ & $10.7826(16)$ & $10.724(3)$ \\
\hline$b[\AA]$ & $15.468(3)$ & $13.6987(7)$ & $13.3648(9)$ & $13.317(3)$ & $15.2874(9)$ & $11.6388(17)$ & $15.738(4)$ \\
\hline$c[\AA]$ & $14.523(3)$ & $13.8370(7)$ & $27.8747(19)$ & $13.577(3)$ & $17.1567(10)$ & $11.6533(17)$ & $17.310(4)$ \\
\hline$\alpha\left[^{\circ}\right]$ & 90 & 90 & $92.8340(10)$ & $64.277(3)$ & 90 & $109.684(2)$ & 90 \\
\hline$\beta\left[^{\circ}\right]$ & $100.380(8)$ & $112.0530(10)$ & $96.215(2)$ & $75.544(3)$ & $93.8610(10)$ & $94.916(2)$ & 90 \\
\hline$\gamma\left[{ }^{\circ}\right]$ & 90 & 90 & $100.443(2)$ & $71.472(3)$ & 90 & $104.023(2)$ & 90 \\
\hline $\mathrm{V}\left[\AA^{3}\right]$ & $1829.9(7)$ & $2412.7(2)$ & $2547.7(3)$ & $1361.2(5)$ & $2360.9(2)$ & $1313.4(3)$ & $2921.7(12)$ \\
\hline $\mathrm{Z}$ & 2 & 4 & 4 & 2 & 4 & 2 & 4 \\
\hline$\rho_{\text {calcd }}\left[\mathrm{g} \mathrm{cm}^{-3}\right]$ & 2.288 & 2.083 & 2.009 & 1.958 & 2.078 & 1.971 & 1.978 \\
\hline$\mu_{\text {palcd }}\left[\mathrm{mm}^{-1}\right]$ & 4.821 & 6.875 & 3.590 & 6.102 & 6.938 & 6.243 & 3.150 \\
\hline$\theta_{\min }, \theta_{\max },\left[^{\circ}\right]$ & $2.12,30.14$ & $1.78,26.37$ & $1.61,31.21$ & $1.68,24.44$ & $1.79,26.38$ & $1.89,26.44$ & $1.91,33.64$ \\
\hline $\begin{array}{l}\text { Total } \\
\text { reflections }\end{array}$ & 14287 & 13455 & 33111 & 7628 & 13261 & 8514 & 16117 \\
\hline $\begin{array}{l}\text { Data/restr./ } \\
\text { param. }\end{array}$ & $\begin{array}{l}4135 / 78 / \\
264\end{array}$ & $4876 / 0 / 338$ & $12370 / 28 / 708$ & 4443 / 25 / 392 & $\begin{array}{l}4764 / 0 / \\
337\end{array}$ & $5216 / 0 / 365$ & $4361 / 36 / 228$ \\
\hline$F(000)$ & 1184 & 1448 & 1480 & 776 & 1416 & 752 & 1683 \\
\hline $\mathrm{T}_{\min } / \mathrm{T}_{\max }$ & 0.798 & 0.288 & 0.875 & 0.689 & 0.654 & 0.655 & 0.905 \\
\hline $\begin{array}{l}\text { Cryst. size } \\
{\left[\mathrm{mm}^{3}\right]}\end{array}$ & $\begin{array}{l}0.06 \times 0.04 \times \\
0.01\end{array}$ & $0.35 \times 0.09 \times 0.06$ & $0.07 \times 0.06 \times 0.03$ & $0.15 \times 0.08 \times 0.06$ & $\begin{array}{l}0.20 \times 0.15 \times \\
0.11\end{array}$ & $\begin{array}{l}0.11 \times 0.09 \times \\
0.03\end{array}$ & $0.05 \times 0.03 \times 0.02$ \\
\hline $\mathrm{R}_{1}[I>2 \sigma(I)]^{a}$ & 0.0576 & 0.0256 & 0.0449 & 0.0403 & 0.0336 & 0.0292 & 0.0438 \\
\hline$w_{2}$ (all data $^{a}$ & 0.1366 & 0.0688 & 0.1166 & 0.0956 & 0.0779 & 0.0706 & 0.1241 \\
\hline $\mathrm{GOF}^{a}$ & 1.151 & 1.039 & 1.108 & 1.020 & 1.333 & 0.997 & 1.143 \\
\hline
\end{tabular}




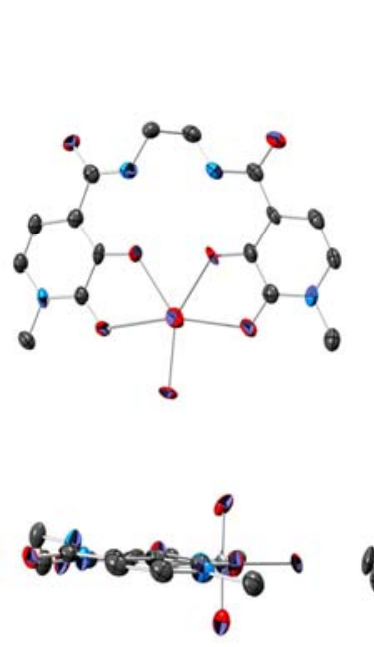

(a)

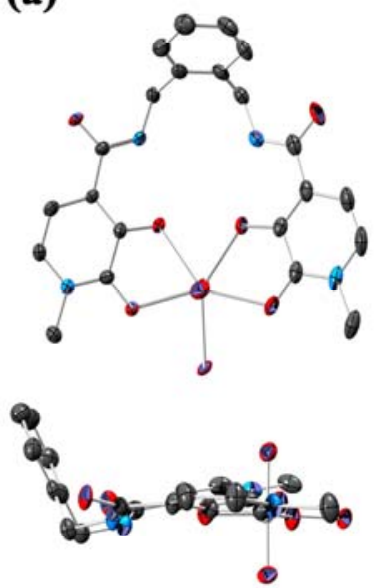

(e)
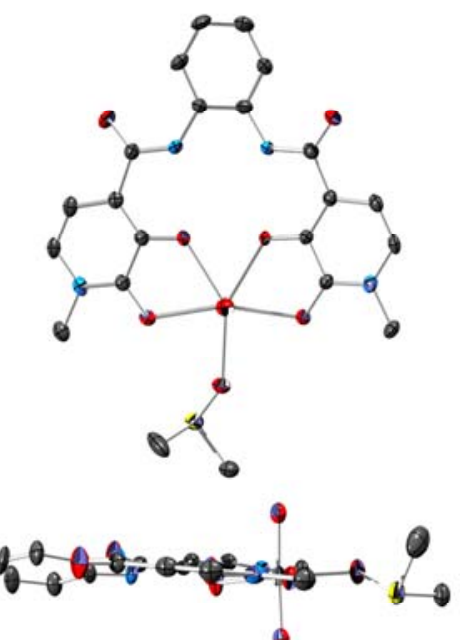

(b)

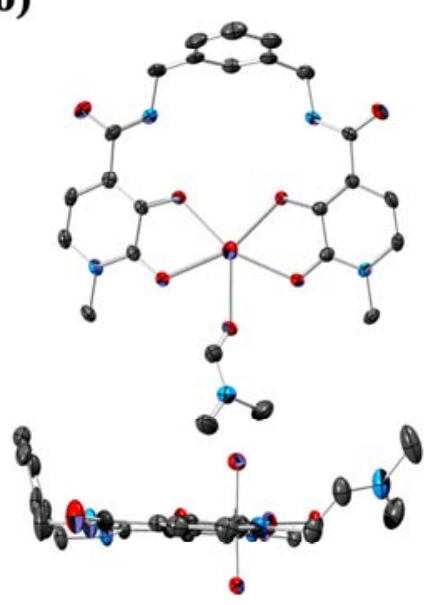

(f)

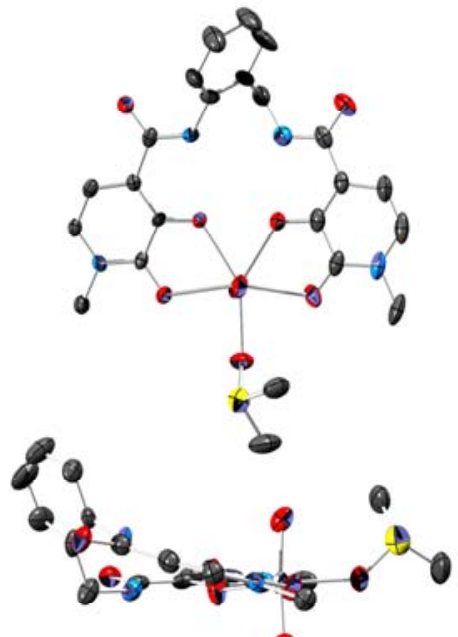

(c)


(d)

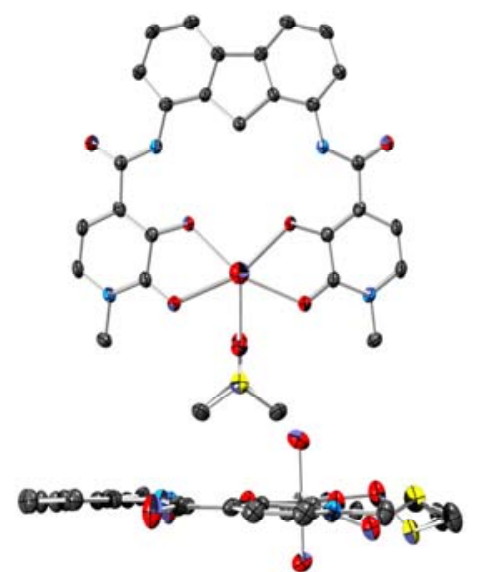

(g)

Figure 2. Top and side views of the crystal structures of the uranyl complexes with (a) $\mathbf{L}^{\mathbf{1}}$; (b) $\mathbf{L}^{\mathbf{3}}$; (c) $\mathbf{L}^{4}$; (d) $\mathbf{L}^{9}$; (e) $\mathbf{L}^{10}$; (f) $\mathbf{L}^{11}$; (g) $\mathbf{L}^{12}$. Thermal ellipsoids are drawn at the $50 \%$ probability level. Hydrogen atoms and non-coordinating solvent molecules are omitted for clarity; disorder in coordinated solvents is included. Oxygen atoms are red, carbons gray, nitrogens blue, sulfurs yellow, and uranium silver.

In a result consistent with prior studies, ${ }^{23}$ the bis-Me-3,2-HOPO ligands in Figure 2 bind the uranyl in a tetradentate, mononuclear fashion with the two Me-3,2-HOPO moieties chelating the uranyl via four oxygen atoms perpendicular to the $\mathrm{O}=\mathrm{U}=\mathrm{O}$ vector. A fifth coordinating oxygen is typically provided by a molecule of solvent from the crystallization solution, resulting in an overall equatorial pentagonal planar coordination mode about the uranyl cation. In most cases the coordinated solvent is DMF or DMSO, although the complex with $\mathbf{L}^{9}$ contains a coordinated methanol. The two complexes $\mathrm{UO}_{2}\left(\mathbf{L}^{1}\right)$ and $\mathrm{UO}_{2}\left(\mathbf{L}^{\mathbf{1 0}}\right)$ appear in Figure 2 to be coordinated by a water molecule, but in fact the 
coordinating oxygen is an amide oxygen from another $\mathrm{UO}_{2}$ (bis-Me-3,2-HOPO) moiety in the crystal, resulting in one-dimensional coordination polymer chains in the crystal lattice. ${ }^{35}$ Because these complexes are soluble in DMSO and DMF, the polymeric structure must be a strictly solid state phenomenon, with the coordination plane in both species completed by a solvent molecule. In all cases, the uranyl cation deviates no more than $5^{\circ}$ from linearity, with an average $\mathrm{U}=\mathrm{O}_{\mathrm{oxo}}$ bond distance of 1.78 $\AA$ that varies a maximum of $0.02 \AA$ intermolecularly. Cursory inspection of the crystal structures reveals that the degree of co-planarity of the HOPO moieties varies depending on the linker used, which is consistent with other $\mathrm{UO}_{2}$ (bis-Me-3,2-HOPO) structures. ${ }^{22,23}$

A point of comparison is necessary for further structural analysis, and the one chosen for the purpose of this study is the previously reported $\mathrm{UO}_{2}(\mathrm{Pr}-\mathrm{Me}-3,2-\mathrm{HOPO})_{2}(\mathrm{DMF})$ structure. ${ }^{23}$ This was chosen because it displays the coordination preferences of the Me-3,2-HOPO with the uranyl cation, while being unconstrained by the geometric requirements imposed by a linker between the chelating moieties. Table 2 compares the equatorial $\mathrm{U}-\mathrm{O}$ bond distances in the $\mathrm{UO}_{2}$ (bis-Me-3,2-HOPO) complexes against those in the untethered $\mathrm{UO}_{2}(\mathrm{Pr}-\mathrm{Me}-3,2-\mathrm{HOPO})_{2}(\mathrm{DMF})$ complex [included in these and subsequent comparisons is the previously reported $\mathrm{UO}_{2}\left(\mathbf{L}^{2}\right)(\mathrm{DMF})$ complex $] .{ }^{22}$ Despite the variety of backbone geometries in each of these complexes, the equatorial $\mathrm{U}-\mathrm{O}$ bonds exhibit maximum variations of only ca. $0.07 \AA$ within each bond type. A comparable intramolecular distance variation of $0.05 \AA$ is observed in the $\mathrm{U}-\mathrm{O}_{\text {amide }}$ bonds in the unconstrained $\mathrm{UO}_{2}(\mathrm{Pr}-\mathrm{Me}-3,2-\mathrm{HOPO})_{2}(\mathrm{DMF})$ complex alone, so the $\mathrm{U}-\mathrm{O}$ bond variations between ligands of differing backbone geometries cannot be considered significant and do not provide predictive information on the relative uranyl affinity of the various bis-Me-3,2-HOPO ligands.

Table 2. Equatorial $\mathrm{U}-\mathrm{O}$ bond distances in $\mathrm{UO}_{2}$ (bis-Me-3,2-HOPO) crystal structures.

\begin{tabular}{|c|c|c|}
\hline Complex & $\mathbf{U}-\mathbf{O}_{\text {amide, }}[\AA \mathbf{\AA}]$ & $\mathbf{U}-\mathbf{O}_{\text {phenolate }},[\AA]$ \\
\hline $\mathrm{UO}_{2}(\mathrm{Pr}-\mathrm{Me}-3,2-\mathrm{HOPO})_{2}{ }^{[23]}$ & $2.457(5), 2.407(5)$ & $2.329(5), 2.329(5)$ \\
\hline $\mathrm{UO}_{2}\left(\mathbf{L}^{1}\right)$ & $2.471(8), 2.442(8)$ & $2.301(7), 2.383(7)$ \\
\hline $\mathrm{UO}_{2}\left(\mathbf{L}^{2}\right)(\mathrm{DMF})^{[22]}$ & $2.437(7), 2.431(6)$ & $2.337(7), 2.350(7)$ \\
\hline
\end{tabular}




\begin{tabular}{|c|c|c|}
\hline $\mathrm{UO}_{2}\left(\mathbf{L}^{3}\right)(\mathrm{DMSO})$ & $2.446(3), 2.458(3)$ & $2.349(3), 2.330(3)$ \\
\hline $\mathrm{UO}_{2}\left(\mathbf{L}^{4}\right)(\mathrm{DMSO})^{a}$ & $2.464(4), 2.450(4) ;$ & $2.306(4), 2.362(4) ;$ \\
\hline $\mathrm{UO}_{2}\left(\mathbf{L}^{9}\right)(\mathrm{MeOH})$ & $2.447(5), 2.477(4)$ & $2.319(6), 2.374(5)$ \\
\hline $\mathrm{UO}_{2}\left(\mathbf{L}^{10}\right)$ & $2.461(5), 2.417(5)$ & $2.320(5), 2.341(5)$ \\
\hline $\mathrm{UO}_{2}\left(\mathbf{L}^{11}\right)(\mathrm{DMF})$ & $2.416(3), 2.432(4)$ & $2.364(4), 2.331(4)$ \\
\hline $\mathrm{UO}_{2}\left(\mathbf{L}^{12}\right)(\mathrm{DMSO})^{b}$ & $2.427(3), 2.429(3)$ & $2.357(3), 2.353(3)$ \\
\hline
\end{tabular}

${ }^{a}$ The crystal contained two unique uranyl complexes.

${ }^{b}$ Only one half of the complex is crystallographically unique.

The crystal structures in Figure 2 exhibit a significant amount of variation in the equatorial O-U-O angles, which are numbered according to Figure 3 and are compared against those in the $\mathrm{UO}_{2}(\operatorname{Pr}-\mathrm{Me}-$ 3,2-HOPO $)_{2}(\mathrm{DMF})$ complex in Table 3. Angles $\sigma_{2}$ and $\sigma_{5}$ correspond to the bite angles of the HOPO moieties, and are constant at $c a .66(2)^{\circ}$, indicating that the coordination mode of the Me-3,2-HOPO moiety does not vary significantly despite the variation in $n$ and ligand geometry. $\sigma_{1}$ is the $\mathrm{O}_{\text {phenolate }}-\mathrm{U}_{-}$ $\mathrm{O}_{\text {phenolate }}$ bond angle, which can be considered an overall ligand bite angle and is in large part dictated by the linker geometry and how closely it holds the HOPO moieties; $\sigma_{1}$ increases with increasing $n$. The reverse trend is seen in the angles to either side of the coordinated solvent oxygen $\left(\sigma_{3}\right.$ and $\left.\sigma_{4}\right)$. The sum of $\sigma_{3}$ and $\sigma_{4}$ is thus a measure of the solvent accessibility of the uranyl cation, which increases as ligand bite angle decreases. A larger solvent accessibility could allow the coordination of larger coordinating molecules, feasibly even chelating moieties with small bite angles (e.g. acetate ${ }^{19}$ or nitrate ${ }^{17} 52.2^{\circ}$, $52.8^{\circ}$ respectively)

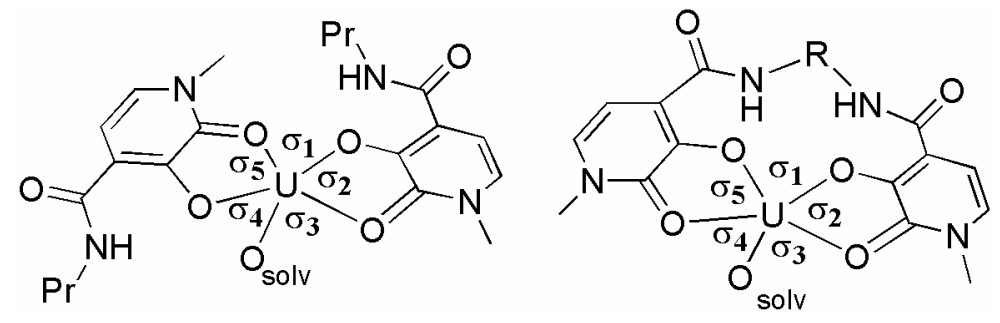

Figure 3. Equatorial $\mathrm{O}-\mathrm{U}-\mathrm{O}$ bond angle designations for $\mathrm{UO}_{2}(\mathrm{Pr}-\mathrm{Me}-3,2-\mathrm{HOPO})_{2}(\mathrm{DMF})$ (left) and $\mathrm{UO}_{2}$ (bis-Me-3,2-HOPO)(solv.) (right), tabulated in Table 3. Uranyl oxo atoms are removed for clarity.

Table 3. $\mathrm{O}-\mathrm{U}-\mathrm{O}$ angles in the uranyl coordination plane in $\mathrm{UO}_{2}($ bis-Me-3,2-HOPO) crystal structures. Angle designations correspond to those in Figure 3.

\begin{tabular}{|c|l|l|l|l|l|l|l|}
\hline Complex & $n^{a}$ & $\sigma_{1},\left[^{\circ}\right]$ & $\sigma_{2},\left[^{\circ}\right]$ & $\sigma_{3},\left[^{\circ}\right]$ & $\sigma_{4},\left[^{\circ}\right]$ & $\sigma_{5},\left[^{\circ}\right]$ & $\sigma_{3}+\sigma_{4},\left[^{\circ}\right]$ \\
\hline $\mathrm{UO}_{2}(\operatorname{Pr}-M e-3,2-$ & -- & $76.8(2)$ & $66.6(2)$ & $76.1(2)$ & $74.2(2)$ & $66.4(2)$ & $150.3(2)$ \\
\hline
\end{tabular}




\begin{tabular}{|c|l|l|l|l|l|l|l|}
\hline $\mathrm{HOPO})_{2}^{[23]}$ & & & & & & & \\
\hline $\mathrm{UO}_{2}\left(\mathbf{L}^{1}\right)$ & 2 & $66.3(3)$ & $65.2(3)$ & $76.6(3)$ & $87.9(3)$ & $64.8(3)$ & $164.1(3)$ \\
\hline $\mathrm{UO}_{2}\left(\mathbf{L}^{2}\right)(\mathrm{DMF})^{[22]}$ & 2 & $65.2(2)$ & $65.0(3)$ & $81.7(3)$ & $82.1(2)$ & $66.2(2)$ & $163.7(3)$ \\
\hline $\mathrm{UO}_{2}\left(\mathbf{L}^{3}\right)(\mathrm{DMSO})$ & 2 & $65.7(1)$ & $65.83(9)$ & $84.5(1)$ & $78.8(1)$ & $65.9(1)$ & $162.8(1)$ \\
\hline $\mathrm{UO}_{2}\left(\mathbf{L}^{4}\right)(\mathrm{DMSO})^{b}$ & 3 & $66.6(2) ;$ & $65.6(2) ;$ & $77.2(2) ;$ & $85.0(2) ;$ & $66.0(2) ;$ & $162.1(2) ;$ \\
\hline $\mathrm{UO}_{2}\left(\mathbf{L}^{9}\right)(\mathrm{MeOH})$ & 4 & $75.4(2)$ & $65.2(2)$ & $84.5(2)$ & $79.9(2)$ & $65.8(2)$ & $163.3(2)$ \\
\hline $\mathrm{UO}_{2}\left(\mathbf{L}^{10}\right)$ & 4 & $73.7(1)$ & $65.8(1)$ & $75.7(1)$ & $78.7(1)$ & $66.8(1)$ & $153.4(1)$ \\
\hline $\mathrm{UO}_{2}\left(\mathbf{L}^{11}\right)(\mathrm{DMF})$ & 5 & $92.8(1)$ & $66.2(1)$ & $67.4(1)$ & $67.9(1)$ & $66.0(1)$ & $134.9(1)$ \\
\hline $\mathrm{UO}_{2}\left(\mathbf{L}^{12}\right)(\mathrm{DMSO})$ & 5 & $94.1(1)$ & $65.51(9)$ & $67.73(7)$ & $67.73(7)$ & $65.51(9)$ & $134.7(1)$ \\
\hline
\end{tabular}

${ }^{a}$ Number of carbons between amide nitrogens in linker.

${ }^{b}$ The crystal contained two unique uranyl complexes.

In addition to the variable ligand bite angle about the uranyl cation, each ligand clearly exhibits a different amount of flexibility; some ligands appear completely planar, while others bend either their Me-3,2-HOPO moieties or aromatic linkers out of the uranyl coordination plane. In order to better compare and quantify the relative distortions exhibited in these structures, a series of metrics was developed that are illustrated in Figure 4. The first, $\theta$, is the angular deviation between the two HOPO moieties as defined by the least squares plane containing the HOPO ring nitrogen and the five ring carbons; $\theta$ is in effect a measure of pucker or ruffle in the ligand geometry. Because the unconstrained $\mathrm{UO}_{2}(\mathrm{Pr}-\mathrm{Me}-3,2-\mathrm{HOPO})_{2}(\mathrm{DMF})$ complex is a very nearly flat complex, high $\theta$ values are most likely a sign that the backbone geometric constraints are not complementary to the uranyl coordination preferences.
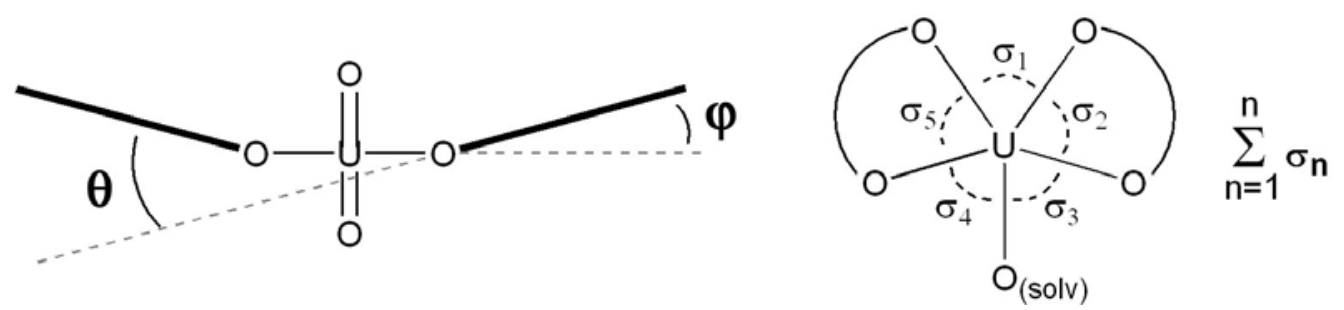

Figure 4. Conformational metrics used to compare the $\mathrm{UO}_{2}$ (bis-Me-3,2-HOPO) structures.

The second evaluated metric, $\varphi$, represents the angular deviation between the least squares plane of each Me-3,2-HOPO ring and the uranyl coordination plane as defined by the least squares plane that includes the five equatorially coordinated oxygen atoms. As with $\theta$, a low $\varphi$ value is consistent with a planar coordination mode of the Me-3,2-HOPO moiety, while a high $\varphi$ indicates ligand ruffling and by 
extension, a disagreement between the ligand geometry and uranyl coordination preferences.

The third metric, $\Sigma \sigma_{\mathrm{n}}$, corresponds to the total equatorial angle sum about the uranyl cation. In perfectly planar uranyl coordination, the sum $\left(\Sigma \sigma_{\mathrm{n}}\right)$ of angles $\sigma_{1}$ through $\sigma_{5}$ would be $360^{\circ}$. If coordination about the uranyl plane becomes crowded due to ligand geometry or steric hindrance, the coordinating oxygens can move out of planarity, and thus the total angle sum about the uranyl cation would necessarily be greater than $360^{\circ}$, with larger values indicating a more strained structure. Large differences in $\Sigma \sigma_{\mathrm{n}}$ are not expected because the coordination environment is not solely dictated by the bis-Me-3,2-HOPO ligand geometry; the fifth coordination site is occupied without exception by a separate molecule - typically solvent - that coordinates to the uranyl cation free from the steric constraints of the bis-Me-3,2-HOPO ligand, giving rise to only small differences in $\Sigma \sigma_{\mathrm{n}}$. Because the current study attempts to find a rigid ligand that best complements the uranyl coordination geometry, structures in which the metrics above approach their minimum possible values $\left(0^{\circ}\right.$ for $\theta$ and $\varphi$, and $360^{\circ}$ for $\Sigma \sigma_{n}$ ), while at the same time providing a relatively rigid ligand scaffold, can be considered to provide optimal geometric complimentarity to the uranyl coordination preferences.

Table 4. Conformational parameters measured from $\mathrm{UO}_{2}$ (bis-Me-3,2-HOPO) crystal structures.

\begin{tabular}{|c|c|c|c|c|}
\hline Complex & $n^{a}$ & $\theta,\left[^{\circ}\right]$ & $\varphi,\left[^{\circ}\right]$ & $\Sigma \sigma_{\mathrm{n}},\left[^{\circ}\right]$ \\
\hline $\begin{array}{c}\mathrm{UO}_{2}(\mathrm{Pr}-\mathrm{Me}-3,2- \\
\mathrm{HOPO})_{2}{ }^{[23]}\end{array}$ & -- & $8.71(9)$ & $6.00(7), 2.90(4)$ & $360.1(4)$ \\
\hline $\mathrm{UO}_{2}\left(\mathbf{L}^{1}\right)$ & 2 & $1.6(7)$ & $9.1(5), 10.1(5)$ & $360.8(7)$ \\
\hline $\mathrm{UO}_{2}\left(\mathbf{L}^{2}\right)(\mathrm{DMF})^{[22]}$ & 2 & $5.8(4)$ & $2.8(4), 7.1(3)$ & $360.2(5)$ \\
\hline $\mathrm{UO}_{2}\left(\mathbf{L}^{3}\right)(\mathrm{DMSO})$ & 2 & $9.43(5)$ & $6.35(3), 12.59(4)$ & $360.7(2)$ \\
\hline $\mathrm{UO}_{2}\left(\mathbf{L}^{4}\right)(\mathrm{DMSO})^{b}$ & 3 & $\begin{array}{l}22.0(1) \\
12.2(2)\end{array}$ & $\begin{array}{c}11.10(8), 14.4(1) \\
8.6(2), 14.0(2)\end{array}$ & $\begin{array}{l}360.4(4) ; \\
361.8(4)\end{array}$ \\
\hline $\mathrm{UO}_{2}\left(\mathbf{L}^{9}\right)(\mathrm{MeOH})$ & 4 & $10.5(5)$ & $0.7(4), 10.0(4)$ & $360.1(4)$ \\
\hline $\mathrm{UO}_{2}\left(\mathbf{L}^{\mathbf{1 0}}\right)$ & 4 & $21.4(2)$ & $8.4(2), 14.1(2)$ & $360.7(2)$ \\
\hline $\mathrm{UO}_{2}\left(\mathbf{L}^{11}\right)(\mathrm{DMF})$ & 5 & $5.6(3)$ & $1.4(2), 6.0(2)$ & $360.3(2)$ \\
\hline $\mathrm{UO}_{2}\left(\mathbf{L}^{\mathbf{1 2}}\right)(\mathrm{DMSO})^{c}$ & 5 & $8.9(2)$ & $5.7(2)$ & $360.6(2)$ \\
\hline
\end{tabular}

${ }^{a}$ Number of carbons between amide nitrogens in linker.

${ }^{b}$ The crystal contains two unique uranyl complexes.

${ }^{c}$ Only one half of the complex is crystallographically unique, giving rise to only one $\varphi$ value.

The conformational parameter values for $\mathrm{UO}_{2}($ bis-Me-3,2-HOPO) structures are listed in Table 4 along with $n$ and are compared against those of the $\mathrm{UO}_{2}(\mathrm{Pr}-\mathrm{Me}-3,2-\mathrm{HOPO})_{2}(\mathrm{DMF})$ structure. Despite 
being unconstrained by a linker, $\mathrm{UO}_{2}(\mathrm{Pr}-\mathrm{Me}-3,2-\mathrm{HOPO})_{2}(\mathrm{DMF})$ displays larger than expected $\theta$ and $\varphi$ values, indicating that small deviations do not necessarily represent a poor geometric agreement between ligand geometry and uranyl coordination preferences. However, the total equatorial angle sum $\Sigma \sigma_{\mathrm{n}}$ is ideal within error. Because the uranyl complexes with 3Li-, 4Li-, and 5Li-Me-3,2-HOPO are reported to have $\theta$ values of $38.86^{\circ}, 9.68^{\circ}$, and $13.40^{\circ}$ respectively, ${ }^{23}$ and because $4 \mathrm{Li}-\mathrm{Me}-3,2-\mathrm{HOPO}$ exhibited the closest approach to the overall geometry seen in the $\mathrm{UO}_{2}(\mathrm{Pr}-\mathrm{Me}-3,2-\mathrm{HOPO})_{2}(\mathrm{DMF})$ complex, deviations in $\theta$ and $\varphi$ greater than $10^{\circ}$ were interpreted as indications that the ligand geometries are significantly warped about the uranyl cation.

Additionally, the $\Sigma \sigma_{\mathrm{n}}$ values in all the bis-Me-3,2-HOPO complexes evaluated are within $1^{\circ}$ of ideal with the exception of one of the two crystallographically unique $\mathrm{UO}_{2}\left(\mathrm{~L}^{4}\right)(\mathrm{DMSO})$ complexes. As expected, the coordinating solvent molecule, free from geometric constraints, does not impose coordinative crowding upon completing the pentagonal planar coordination geometry about the uranyl cation. The $\mathrm{U}-\mathrm{O}_{\text {solv }}$ distances also show little variation with changing $n$ or ligand bite angles, with the $\mathrm{U}-\mathrm{O}_{\mathrm{DMSO}}, \mathrm{U}-\mathrm{O}_{\mathrm{DMF}}$, and $\mathrm{U}-\mathrm{O}_{\text {amide }}$ distances varying a maximum of only $0.03 \AA, 0.06 \AA$, and $0.01 \AA$, respectively, over the series of $\mathrm{UO}_{2}$ (bis-Me-3,2-HOPO) structures in Figure 2 as well as those previously published. ${ }^{23}$ Thus, coordinative crowding is not a significant concern with the bis-Me-3,2HOPO ligands investigated in this study.

\section{Conformational analysis of $n=2$ complexes $\mathrm{UO}_{2}\left(\mathrm{~L}^{1}\right), \mathrm{UO}_{2}\left(\mathrm{~L}^{2}\right)(\mathrm{DMF})$, and $\mathrm{UO}_{2}\left(\mathrm{~L}^{3}\right)(\mathrm{DMSO})$.}

Comparison of the one-dimensional polymeric structure of $\mathrm{UO}_{2}\left(\mathbf{L}^{1}\right)$ to that of $\mathrm{UO}_{2}(\mathrm{Pr}-\mathrm{Me}-3,2-$ $\mathrm{HOPO})_{2}(\mathrm{DMF})$ reveals that the consequence of the ligand geometry in $\mathbf{L}^{\mathbf{1}}$ is a very co-planar coordination mode about the uranyl cation. The $\theta$ value is artificially low because unlike every other $\mathrm{UO}_{2}$ (bis-Me-3,2-HOPO) structure evaluated here or elsewhere, the Me-3,2-HOPO planes bend in opposite directions, resulting in an almost parallel arrangement of the Me-3,2-HOPO moieties. Thus, the 
more appropriate value to inspect is $\varphi$, which still adopts comparable values to those in the $\mathrm{UO}_{2}(\mathrm{Pr}-\mathrm{Me}-$ 3,2-HOPO $)_{2}(\mathrm{DMF})$ complex. The $2 \mathrm{Li}$ backbone in $\mathbf{L}^{\mathbf{1}}$ is able to adopt the staggered gauche conformation typical of alkane chains, perhaps causing the Me-3,2-HOPO moieties to bend in opposite directions from each other. However, there are no outward signs of unreasonable ligand distortions in the $\mathrm{UO}_{2}\left(\mathbf{L}^{1}\right)$ complex to dissuade further investigation of this ligand geometry.

The completely rigid ligands $\mathbf{L}^{2}$ and $\mathbf{L}^{3}$ adopt strikingly planar arrangements about the uranyl cation, and the $\theta, \varphi$, and $\Sigma \sigma_{\mathrm{n}}$ values are unsurprisingly low in both complexes. However, considering that $\mathbf{L}^{2}$ and $\mathbf{L}^{3}$ are both fully conjugated and should have similarly inflexible ligand geometries, the differences in the $\theta$ and $\varphi$ values between these complexes are surprisingly large (as much as $10^{\circ}$ for $\varphi$ ). Geometrically, ligands $\mathbf{L}^{2}$ and $\mathbf{L}^{3}$ differ primarily in the angle of attachment between the amide substituents and the aromatic linker ring; ortho substitution angles on a thiophene are ideally $72^{\circ}$, while those for a phenyl ring are $60^{\circ}$. We hypothesize this $12^{\circ}$ difference is the cause of the increased planarity in $\mathrm{UO}_{2}\left(\mathbf{L}^{2}\right)(\mathrm{DMF})$ because the wider 3,4-thiophene substitution angle in $\mathbf{L}^{2}$ separates the amides farther apart than the $o$-phenylene linker in $\mathbf{L}^{3}$. This angular difference results in an increase of $0.07 \AA$ in the $\mathrm{N}_{\text {amide }}-\mathrm{N}_{\text {amide }}$ distance between the $\mathrm{UO}_{2}\left(\mathbf{L}^{2}\right)(\mathrm{DMSO})$ and $\mathrm{UO}_{2}\left(\mathbf{L}^{3}\right)(\mathrm{DMF})$ structures. Upon mononuclear uranyl coordination, intramolecular $\mathrm{N}-\mathrm{H} \cdots \mathrm{O}$ hydrogen bonding is maintained between the linking amides and the Me-3,2-HOPO phenolate oxygens, requiring in turn that the protons on the linking amides point towards each other; the smaller $\mathrm{N}_{\text {amide }}-\mathrm{N}_{\text {amide }}$ distance in $\mathrm{UO}_{2}\left(\mathbf{L}^{3}\right)$ (DMSO) results in a more sterically crowded conformation than that in $\mathrm{UO}_{2}\left(\mathbf{L}^{2}\right)(\mathrm{DMF})$. This steric crowding causes the $\mathrm{N}_{\text {amide }}-\mathrm{C}_{\text {backbone }}$ torsion angle in the $\mathrm{UO}_{2}\left(\mathbf{L}^{3}\right)$ (DMSO) complex to adopt values of $148^{\circ}$ and $157^{\circ}$ to relieve steric interaction between the amide protons. For comparison, the same torsion angles in $\mathrm{UO}_{2}\left(\mathbf{L}^{2}\right)(\mathrm{DMF})$ are $172^{\circ}$ and $176^{\circ}$ (much closer to the ideal $180^{\circ}$ ) because the amide moieties are held farther apart by the thiophene ring of $\mathbf{L}^{2}$ than the phenyl ring of $\mathbf{L}^{3}$. Despite these small differences, 
however, both $\mathbf{L}^{2}$ and $\mathbf{L}^{3}$ exhibit promising geometries for future study.

Conformational analysis of $n=3$ complex $\mathbf{U O}_{2}\left(\mathbf{L}^{4}\right)(\mathbf{D M S O})$. The $\mathrm{UO}_{2}\left(\mathrm{~L}^{4}\right)(\mathrm{DMSO})$ complex displays the highest $\theta, \varphi$, and $\Sigma \sigma_{\mathrm{n}}$ values in Table 4 . The most obvious structural consequence of this backbone choice is the significant deviation of the linker ring from co-planarity with the uranyl coordination plane. This distortion is necessary to bring the Me-3-2-HOPO moieties into binding positions with the uranyl cation, but is not completely successful because the HOPO moieties themselves are also significantly twisted out of the uranyl coordination plane. Thus, although $\mathbf{L}^{4}$ is physically capable of binding the uranyl cation in a mononuclear fashion, it can only do so upon considerable ligand distortion.

Conformational analysis of $n=4$ complexes $\mathrm{UO}_{2}\left(\mathrm{~L}^{9}\right)(\mathrm{MeOH})$ and $\mathrm{UO}_{2}\left(\mathrm{~L}^{10}\right)$. Although the only difference between ligands $\mathbf{L}^{4}$ and $\mathbf{L}^{9}$ is a substitutional shift of the methylene spacer by one carbon on the aromatic linker, the $\mathrm{UO}_{2}\left(\mathbf{L}^{9}\right)(\mathrm{MeOH})$ complex displayed far lower $\theta$, $\varphi$, and $\Sigma \sigma_{\mathrm{n}}$ values than $\mathrm{UO}_{2}\left(\mathbf{L}^{4}\right)(\mathrm{DMSO})$, even exhibiting the lowest measured $\varphi$ value of $0.7^{\circ}$. However, careful investigation of the crystal structure indicates that in order for the ligand to bind in the observed mononuclear fashion, one linking amide rotates $90^{\circ}$ out of co-planarity to the Me-3,2-HOPO moiety to which it is attached. This conformation disrupts an intramolecular hydrogen bond known to stabilize phenols ortho to amide groups upon deprotonation/metal chelation. ${ }^{27}$ This twisted conformation is stabilized in the solid state by a hydrogen-bonding interaction between the twisted amide proton and an amide oxygen from a neighboring molecule in the crystal structure $\left(\mathrm{N}_{\text {amide }}-\mathrm{O}_{\text {amide }}\right.$ distance of $\left.3.06 \AA\right)$, but this structure suggests that the $m$-toluene backbone in $\mathbf{L}^{9}$ requires a high energy distortion to enable mononuclear uranyl chelation.

The one-dimensional polymeric $\mathrm{UO}_{2}\left(\mathbf{L}^{10}\right)$ complex structure exhibits some of the largest reported $\theta$ and $\varphi$ values (Table 4). Mononuclear coordination also requires the $\alpha, \alpha^{\prime}-o$-xylene linker to bend 
significantly out of the uranyl plane, presumably in order to achieve sufficient torsion angles about the methylene spacers to allow close approach of the Me-3,2-HOPO moieties for mononuclear coordination. No significant $\pi$-stacking is observed between HOPO rings or the $o$-xylene backbone, so this poor geometric agreement between the ligand and the uranyl cation seems characteristic of the complex, making the $o$-xylene linker in $\mathbf{L}^{\mathbf{1 0}}$ unattractive for further study.

Conformational analysis of $n=5$ complexes $\mathrm{UO}_{2}\left(\mathrm{~L}^{11}\right)(\mathrm{DMF})$ and $\mathrm{UO}_{2}\left(\mathrm{~L}^{12}\right)(\mathrm{DMSO})$. The aromatic backbone in $\mathrm{UO}_{2}\left(\mathbf{L}^{11}\right)(\mathrm{DMF})$ bends dramatically out of the HOPO and uranyl coordination planes, but unlike $\mathrm{UO}_{2}\left(\mathbf{L}^{10}\right)$, the complex exhibits arguably the most favorable combination of $\theta$, $\varphi$, and $\Sigma \sigma_{\mathrm{n}}$ values in Table 4. Ligands $\mathbf{L}^{\mathbf{1 0}}$ and $\mathbf{L}^{11}$ both contain two methylene spacers between the aromatic linker ring and the amide nitrogens, which are obviously responsible for the ligands' respective abilities to bind the uranyl in a mononuclear fashion despite their large $n$ values. There may exist some weak intermolecular $\pi$-stacking interactions in the crystal lattice between Me-3,2-HOPO moieties (3.4 $\AA$ interplane distance), but no such interaction exists with the backbone phenyl ring, again suggesting that - like in $\mathrm{UO}_{2}\left(\mathbf{L}^{10}\right)$ - the ligand distortion observed is native to the uranyl complex and not solely a result of crystal packing effects. Although significant backbone distortion is required in $\mathbf{L}^{\mathbf{1 0}}$ and $\mathbf{L}^{\mathbf{1 1}}$ for mononuclear chelation, the resultant co-planar arrangement of the HOPO moieties in $\mathrm{UO}_{2}\left(\mathbf{L}^{11}\right)(\mathrm{DMF})$ encourages further study of the $m$-xylene linker geometry both because of its favorable geometric agreements as well as for a point for comparison against the ligands with $n=2$, for which the values in Table 4 were also very favorable. By geometric evaluation, $\mathbf{L}^{\mathbf{1 1}}$ is also more appropriate for uranyl complexation than the linear 5Li-Me-3,2-HOPO ligand, in whose uranyl complex a $\theta$ value of $13.4^{\circ}$ was observed. ${ }^{23}$ Whether the less severe distortion about the uranyl cation with $\mathbf{L}^{11}$ is a result of decreased degrees of freedom compared to $5 \mathrm{Li}-\mathrm{Me}-3,2-\mathrm{HOPO}$ or because gauche interactions and the alkyl torsion angles they require are absent in $\mathbf{L}^{11}$ is unclear. 
The $\mathrm{UO}_{2}\left(\mathbf{L}^{\mathbf{1 2}}\right)(\mathrm{DMSO})$ complex spans a crystallographic 2-fold axis, making only half of the fluorene linker and one Me-3,2-HOPO moiety unique, giving rise to only one value for $\varphi$ in Table 4 . There can be little argument that the low $\theta, \varphi$, and $\Sigma \sigma_{\mathrm{n}}$ values of the $\mathrm{UO}_{2}\left(\mathbf{L}^{11}\right)(\mathrm{DMF})$ complex are made possible by the flexibility of the linker, yet despite its large and completely rigid 1,8-fluorene linker, the $\mathrm{UO}_{2}\left(\mathbf{L}^{12}\right)(\mathrm{DMSO})$ complex exhibits very low $\theta, \varphi$, and $\Sigma \sigma_{\mathrm{n}}$ values that rival those in $\mathrm{UO}_{2}\left(\mathbf{L}^{11}\right)(\mathrm{DMF})$. Additionally, the ligand bite angle $\left(\sigma_{1}\right)$ in $\mathrm{UO}_{2}\left(\mathbf{L}^{12}\right)(\mathrm{DMSO})$ is only one degree larger than that in $\mathrm{UO}_{2}\left(\mathbf{L}^{11}\right)(\mathrm{DMF})$. Compared against the values in Table 4, this suggests that ligand $\mathbf{L}^{12}$ presents a conformation that is very complementary to the uranyl coordination geometry, making the fluorene backbone very attractive for further actinyl coordination studies.

Structural analysis of 1,8-fluorene-Me-3,2-HOPO $\left(\mathbf{L}^{12} \mathbf{H}_{2}\right)$. The rigidity of the 1,8 -fluorene backbone coupled with the favorable conformational parameter measures in the $\mathrm{UO}_{2}\left(\mathbf{L}^{12}\right)(\mathrm{DMSO})$ structure suggests that $\mathbf{L}^{12} \mathbf{H}_{2}$ may be pre-organized for chelation to the uranyl cation. This is corroborated by the similarity between the ligand geometry in $\mathrm{UO}_{2}\left(\mathbf{L}^{12}\right)(\mathrm{DMSO})$ and that in a crystal structure of uncomplexed $\mathbf{L}^{12} \mathbf{H}_{2}$ grown out of DMSO- $d_{6}$ during NMR characterization and shown in Figure 5; crystallographic parameters are listed in Table 5. The asymmetric unit contains a DMSO molecule to which the ligand is hydrogen-bonded through both phenolic oxygens, with $\mathrm{O}_{\mathrm{DMSO}}-\mathrm{O}_{\text {phenol }}$ distances of $2.63 \AA$ and $2.68 \AA$. Because of this hydrogen bonding interaction above the plane of the HOPO rings, there is an unsurprising $43^{\circ}$ deviation between the two HOPO ring planes ( $\theta$ value if it were chelating uranyl), but visual inspection makes it clear that the overall ligand geometry is similar to that seen in $\mathrm{UO}_{2}\left(\mathbf{L}^{\mathbf{1 2}}\right)(\mathrm{DMSO})$. The observed interaction with the DMSO molecule suggests this ligand arrangement is solvent-dependent, but demonstrates that $\mathbf{L}^{12} \mathbf{H}_{2}$ can adopt a free ligand conformation similar to that seen in its uranyl complex. 


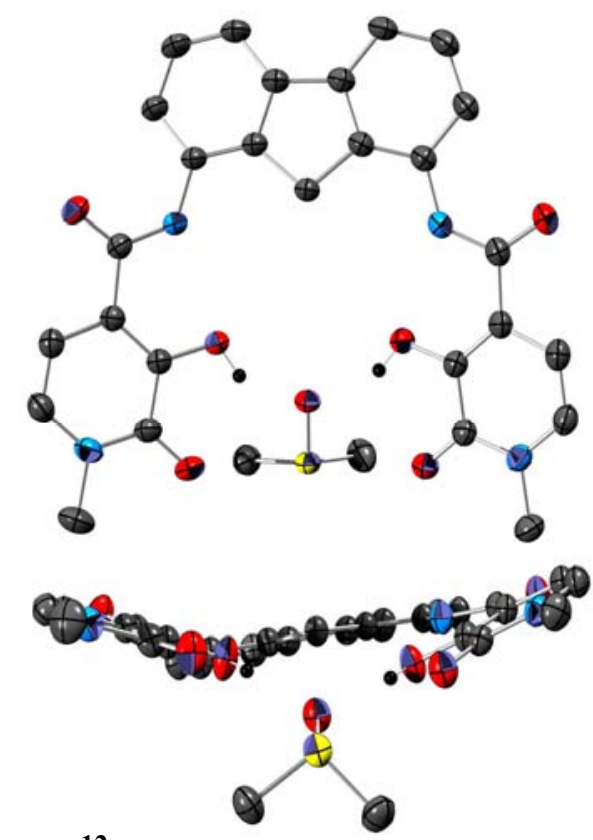

Figure 5. Top and side views of the $\mathbf{L}^{\mathbf{1 2}} \mathbf{H}_{2} \cdot$ DMSO crystal structure. Thermal ellipsoids are drawn at the $50 \%$ probability level. Hydrogen atoms are omitted for clarity except for phenolate hydrogens. Oxygen atoms are red, carbons gray, nitrogens blue, sulfur yellow, and hydrogens are black.

Table 5. Crystallographic parameters for $\mathbf{L}^{\mathbf{1 2}} \mathbf{H}_{2} \cdot$ DMSO.

\begin{tabular}{|c|c|c|c|}
\hline Formula & $\begin{array}{c}\mathrm{C}_{27} \mathrm{H}_{22} \mathrm{~N}_{4} \mathrm{O}_{6} \\
\mathrm{C}_{2} \mathrm{H}_{6} \mathrm{OS}\end{array}$ & $\begin{array}{c}\text { Data/ restr./ } \\
\text { param. }\end{array}$ & $8182 / 15$ / 482 \\
\hline MW & 576.61 & $\mathbf{T}[\mathbf{K}]$ & 193(2) \\
\hline Crystal system & Monoclinic & $\rho_{\text {calcd }}\left[\mathrm{g} \mathrm{cm}^{-3}\right]$ & 1.428 \\
\hline Space group & $\mathrm{P} 2{ }_{1} / \mathrm{n}$ & $\mu_{\text {palcd }}\left[\mathrm{mm}^{-1}\right]$ & 0.218 \\
\hline Appearance & Parallelepiped & $\theta_{\min }, \theta_{\max },\left[^{\circ}\right]$ & $2.14,33.67$ \\
\hline Color & Yellow & Total reflections & 39273 \\
\hline$a[\AA]$ & $10.9305(9)$ & $\mathbf{Z}$ & 4 \\
\hline$b[\AA]]$ & $20.7752(16)$ & $F(000)$ & 1208 \\
\hline$c[\AA]$ & $12.9772(10)$ & $\mathbf{T}_{\min } / \mathbf{T}_{\max }$ & 0.985 \\
\hline$\alpha\left[{ }^{\circ}\right]$ & 90 & Cryst. size $\left[\mathrm{mm}^{3}\right]$ & $0.11 \times 0.07 \times 0.04$ \\
\hline$\beta\left[^{\circ}\right]$ & $114.494(2)$ & $\mathrm{R}_{1}[I>2 \sigma(I)]^{a}$ & 0.0503 \\
\hline$\gamma\left[^{\circ}\right]$ & 90 & $\mathrm{wR}_{2}\left(\right.$ all data) ${ }^{a}$ & 0.1506 \\
\hline $\mathrm{V}\left[\AA^{3}\right]$ & $2681.7(4)$ & GOF $^{a}$ & 1.151 \\
\hline
\end{tabular}

${ }^{1}$ H NMR analysis of hydrogen-bonding capability. Typical of catecholamides and their structural analogs, ${ }^{27} \mathrm{Me}-3,2-\mathrm{HOPO}$ moieties establish intramolecular hydrogen bonds between the linking amide proton and the ortho phenolate oxygen upon deprotonation or metal chelation. This hydrogen bonding is observed in the solid state structures in Figure 2, but is also evidenced by downfield ${ }^{1} \mathrm{H}$ NMR shifts of the amide protons in the uranyl complexes. The extent of this downfield shift is known to vary depending on linker geometry ${ }^{23}$ and how well the resultant complex geometry maintains the stabilizing 
intramolecular hydrogen bond between the amide proton and the coordinated phenolate oxygen. ${ }^{27}$

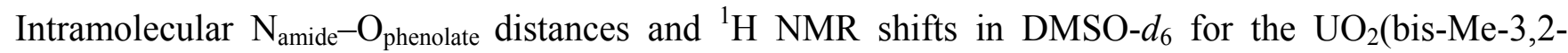
HOPO) complexes are listed in Table 6, including those for the $\mathrm{UO}_{2}(\mathrm{nLi}-\mathrm{Me}-3,2-\mathrm{HOPO})$ complexes. ${ }^{1} \mathrm{H}$ NMR data for the $\mathrm{UO}_{2}\left(\mathbf{L}^{\mathbf{1 2}}\right)$ complex is unavailable because of its poor solubility. The majority of the $\mathrm{N}_{\text {amide }}-\mathrm{O}_{\text {phenolate }}$ distances in Table 6 range between $2.60 \AA$ and $2.77 \AA$, indicating the presence of the expected hydrogen bond. The $\mathrm{N}_{\text {amide }}-\mathrm{O}_{\text {phenolate }}$ distances in $\mathrm{UO}_{2}\left(\mathbf{L}^{\mathbf{1}}\right)$ are the shortest of the nLi-Me-3,2HOPO ligands, corresponding well to the trend observed before in which shortening of linear linkers results in a decrease in $\mathrm{N}_{\text {amide }}-\mathrm{O}_{\text {phenolate }}$ distance. ${ }^{23}$ This also explains the large downfield shift of the amide protons in $\mathrm{UO}_{2}\left(\mathbf{L}^{\mathbf{1}}\right)$, which becomes less severe upon increasing $n$ in complexes with nLi-Me-3,2HOPO ligands.

Table 6. ${ }^{1} \mathrm{H}$ NMR chemical shifts for amide protons in $\mathrm{UO}_{2}$ (bis-Me-3,2-HOPO) complexes in DMSO$d_{6}$.

\begin{tabular}{|c|c|c|c|}
\hline Complex & $n^{a}$ & $\mathbf{N}_{\text {amide }}-\mathbf{O}_{\text {phenolate }}[\mathbf{\AA}]$ & ${ }^{1} \mathbf{H}_{\text {amide }} \delta,[\mathrm{ppm}]$ \\
\hline $\mathrm{UO}_{2}\left(\mathbf{L}^{\mathbf{1}}\right)$ & 2 & $2.63,2.69$ & $10.99^{[23]}$ \\
\hline $\begin{array}{c}\mathrm{UO}_{2}(3 \mathrm{Li}-\mathrm{Me}-3,2- \\
\mathrm{HOPO})^{b[23]}\end{array}$ & 3 & 2.70 & 10.16 \\
\hline $\begin{array}{c}\mathrm{UO}_{2}(4 \mathrm{Li}-\mathrm{Me}-3,2- \\
\mathrm{HOPO})^{c[23]}\end{array}$ & 4 & $2.71,2.71,2.75,2.75$ & 9.26 \\
\hline $\begin{array}{c}\mathrm{UO}_{2}(5 \mathrm{Li}-\mathrm{Me}-3,2- \\
\mathrm{HOPO})^{b[23]}\end{array}$ & 5 & 2.77 & 9.45 \\
\hline $\mathrm{UO}_{2}\left(\mathbf{L}^{2}\right)^{\lfloor 22]}$ & 2 & $2.61,2.63$ & $13.05(\mathrm{~s})$ \\
\hline $\mathrm{UO}_{2}\left(\mathbf{L}^{3}\right)$ & 2 & $2.65,2.69$ & $12.38(\mathrm{~s})$ \\
\hline $\mathrm{UO}_{2}\left(\mathbf{L}^{4}\right)^{d}$ & 3 & $\begin{array}{l}2.60(\mathrm{t}), 2.63(\mathrm{t}), \\
2.67(\mathrm{~s}), 2.68(\mathrm{~s})\end{array}$ & $11.62(\mathrm{~s}), 11.40(\mathrm{t})$ \\
\hline $\mathrm{UO}_{2}\left(\mathbf{L}^{9}\right)^{d}$ & 4 & $2.66(\mathrm{~s}), 3.51(\mathrm{t})$ & $9.14(\mathrm{t}), 13.35(\mathrm{~s})$ \\
\hline $\mathrm{UO}_{2}\left(\mathbf{L}^{10}\right)$ & 4 & $2.72,2.74$ & $10.12(\mathrm{t})$ \\
\hline $\mathrm{UO}_{2}\left(\mathbf{L}^{11}\right)$ & 5 & $2.76,2.77$ & $9.46(\mathrm{t})$ \\
\hline $\mathrm{UO}_{2}\left(\mathbf{L}^{12}\right)^{b}$ & 5 & 2.73 & N/A (insoluble) \\
\hline
\end{tabular}

${ }^{a}$ Number of carbons between amide nitrogens in linker.

${ }^{b}$ Only one half of the complex is crystallographically unique, giving rise to only one N--O distance.

${ }^{c}$ The crystal contains two unique uranyl complexes.

${ }^{d}$ Triplett $(\mathrm{t})$ and singlet $(\mathrm{s})$ notations indicate shifts/distances from methylene and aromatic amides, respectively.

The dramatic outlier in Table 6 is the $3.51 \AA$ distance in $\mathrm{UO}_{2}\left(\mathbf{L}^{9}\right)(\mathrm{MeOH})$ which corresponds to the benzylic amide that is twisted $90^{\circ}$ from the Me-3,2-HOPO plane. This conformation exhibited no intramolecular hydrogen bond in the solid state, and the benzylic amide proton chemical shift of 9.14 ppm supports this structural evidence because it is farther upfield than the benzylic amide protons in 
$\mathrm{UO}_{2}\left(\mathbf{L}^{4}\right), \mathrm{UO}_{2}\left(\mathbf{L}^{11}\right)$, and $\mathrm{UO}_{2}\left(\mathbf{L}^{12}\right)$, illustrating a poorer intramolecular hydrogen bond. This also suggests that the intermolecular hydrogen bonding observed in the solid state does not cause the amide twist, and that the solid state conformation of $\mathrm{UO}_{2}\left(\mathbf{L}^{9}\right)(\mathrm{MeOH})$ persists in solution. This amide twist necessarily represents a high-energy conformation, suggesting the $m$-toluene linker in $\mathbf{L}^{\mathbf{9}}$ is not a promising candidate for future study.

Remarkably, the benzylic amide proton in $\mathrm{UO}_{2}\left(\mathbf{L}^{4}\right)$ shows the largest chemical shift for nonaromatic amides in the uranyl complexes investigated here and previously. ${ }^{23}$ The chemical shift of 11.40 ppm is 1.28 ppm farther downfield than the next lowest benzylic amide shift in $\mathrm{UO}_{2}\left(\mathbf{L}^{\mathbf{1 1}}\right)$, and only 0.22 ppm upfield from the neighboring aromatic amide in $\mathrm{UO}_{2}\left(\mathbf{L}^{4}\right)$. Such a large chemical shift correlates with the benzylic $\mathrm{N}_{\text {amide }}-\mathrm{O}_{\text {phenolate }}$ distances in $\mathrm{UO}_{2}\left(\mathbf{L}^{4}\right)$ being as much as $0.17 \AA$ shorter than those in $\mathrm{UO}_{2}\left(\mathbf{L}^{10}\right)$ and $\mathrm{UO}_{2}\left(\mathbf{L}^{11}\right)$ and even in $\mathrm{UO}_{2}\left(\mathbf{L}^{1}\right)$, which exhibits the next highest chemical shift of nonaromatic amide protons. Thus, while $\mathbf{L}^{4}$ imposes a rather strained coordination geometry about the uranyl cation according to conformational parameters in Table 4, it does seem to adopt a geometry that favors the hydrogen bonding tendencies of bis-Me-3,2-HOPO moieties.

With the exception of the twisted amide in $\mathrm{UO}_{2}\left(\mathbf{L}^{9}\right)$, the uranyl complexes with rigidly-linked bisMe-3,2-HOPO ligands generally display increasing $\mathrm{N}_{\text {amide }}-\mathrm{O}_{\text {phenolate }}$ distances at larger $n$ values, a trend observed previously in the nLi-Me-3,2-HOPO ligands. ${ }^{23}$ Correlating these distances to ${ }^{1} \mathrm{H}$ NMR shifts becomes impossible when considering a combination of the alkyl- and aromatic-linked bis(Me-3,2HOPO) ligands because aromatic amides are expected to exhibit larger downfield shifts than their aliphatic counterparts due to the proximity of the electron-withdrawing aromatic ring, regardless of hydrogen bonding capability. Taking into consideration only the ${ }^{1} \mathrm{H}$ NMR shifts of the alkyl-amides in $\mathrm{UO}_{2}$ (bis-Me-3,2-HOPO) complexes reported here and elsewhere, ${ }^{23}$ a general trend of decreasing ${ }^{1} \mathrm{H}$ NMR shift upon increasing $\mathrm{N}_{\text {amide }}-\mathrm{O}_{\text {phenolate }}$ distance (which itself is related to the value of $n$ ) is observed 
(Figure 6). Thus, taking into account only hydrogen-bonding capacity of bis-Me-3,2-HOPO ligands, smaller linkers typically optimize this interaction.

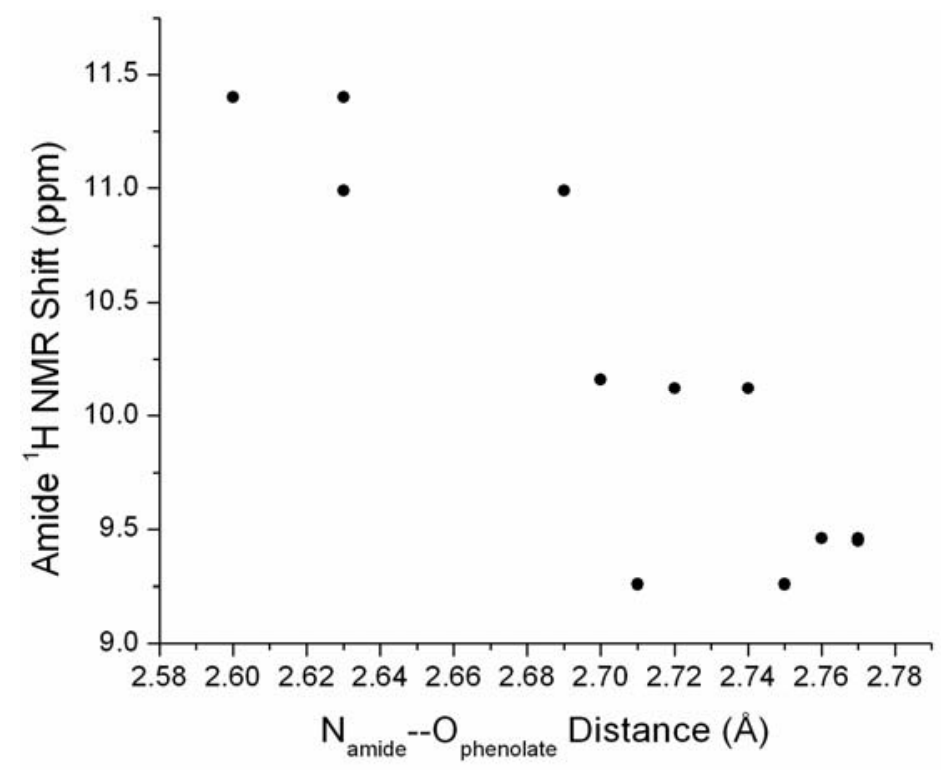

Figure 6. Alkyl-amide ${ }^{1} \mathrm{H}$ NMR chemical shifts in $\mathrm{UO}_{2}$ (bis-Me-3,2-HOPO) complexes. The anomalously upfield amide signal from $\mathrm{UO}_{2}\left(\mathbf{L}^{9}\right)$ is omitted due to lack of intramolecular hydrogen bonding.

Applying this trend to aromatic linkers suggests that hydrogen-bonding interactions should be optimized in complexes with ligands $\mathbf{L}^{2}$ and $\mathbf{L}^{3}(n=2)$, in which the amide proton chemical shifts are among the largest in Table 6 . There is a difference of $c a .0 .7 \mathrm{ppm}$ between the amide resonances in the uranyl complexes with $\mathbf{L}^{2}$ and $\mathbf{L}^{3}$, but because their uncomplexed amide proton resonances are 10.08 ppm and $10.09 \mathrm{ppm}$, respectively, the difference in complexed proton shift is most likely a result of the geometric differences between the two linkers and its consequences on intramolecular hydrogen bonding, and does not stem from a difference in linker electronics. As mentioned before, the ortho substitution angle on a thiophene is $12^{\circ}$ larger than on a benzene, and thus we hypothesize that increased distance between the linking amides is the cause for the optimized hydrogen bonding in $\mathrm{UO}_{2}\left(\mathbf{L}^{2}\right)$ compared to $\mathrm{UO}_{2}\left(\mathbf{L}^{3}\right)$; the larger amide torsion angle and subsequent decreased co-planarity with the uranyl coordination plane in $\mathrm{UO}_{2}\left(\mathbf{L}^{3}\right)(\mathrm{DMSO})$ compared to $\mathrm{UO}_{2}\left(\mathbf{L}^{2}\right)(\mathrm{DMF})$ discussed above is the corresponding geometric consequence of this small substitution angle difference, and the increased 
planarity allows for optimal hydrogen-bonding capabilities upon uranyl complexation by $\mathbf{L}^{2}$.

The aromatic amide proton in $\mathrm{UO}_{2}\left(\mathbf{L}^{9}\right)$ displays an even larger downfield shift than that seen in $\mathrm{UO}_{2}\left(\mathbf{L}^{2}\right)(\mathrm{DMF})$ and $\mathrm{UO}_{2}\left(\mathbf{L}^{3}\right)(\mathrm{DMSO})$, which opposes the general trend of forming stronger hydrogen bonds upon decreasing $n$ and thus requires some attention. However, the $\mathrm{UO}_{2}\left(\mathbf{L}^{9}\right)(\mathrm{MeOH})$ complex is the only mononuclear $\mathrm{UO}_{2}$ (bis-Me-3,2-HOPO) complex known in which an $\mathrm{N}_{\text {amide }}-\mathrm{O}_{\text {phenoate }}$ hydrogen bond is abandoned due to geometric constraints. Thus, the resultant ligand geometry seems the result of the ligand's attempts to optimize the one remaining hydrogen bond to lower the overall conformational energy, which in turn results in the large downfield aromatic amide proton resonance.

Conclusions. Crystal structure analysis of the uranyl complexes with several bis-Me-3,2-HOPO ligands has revealed many trends about this ligand series that will help in future ligand design strategies for the uranyl cation with bis-bidentate ligand scaffolds. Ligands with very constrained linkers that position their chelating moieties either far apart or close together $\left(\mathbf{L}^{5} \mathbf{H}_{\mathbf{2}}\right.$ through $\left.\mathbf{L}^{8} \mathbf{H}_{2}\right)$ were found to be inappropriate for mononuclear uranyl chelation. Ligands with $n=3$ or $n=4$ also exhibited rather strained ligand conformations upon mononuclear coordination, even sacrificing an intramolecular hydrogen bonding interaction. Ligands incorporating short $(n=2)$ or long $(n=5)$ linkers - both flexible and rigid - exhibited the most planar coordination modes about the uranyl cation without sacrificing intramolecular hydrogen bonding and without adopting strained ligand geometries.

${ }^{1} \mathrm{H}$ NMR comparison between the uranyl complexes provides insight into the optimization of intramolecular hydrogen bonding, indicating that it generally decreases (as measured by $\mathrm{N}_{\text {amide }}-\mathrm{O}_{\text {phenolate }}$ distances) as linker length increases. Of the short $(n=2)$ linkers, the 3,4-thiophene linker was shown to provide an optimal intramolecular hydrogen bonding interaction, likely due to the substitutional angles of the amides at the thiophene ring that result in its favorable geometric arrangement about the uranyl cation. 
Of the linkers investigated, 3,4-thiophene and $o$-phenylene exhibit the most promise as linkers for actinyl-selective ligands because they provide very planar coordination modes about the uranyl cation and also maintain strong intramolecular hydrogen bonding interactions. As a point of comparison, the $m$-xylene backbone in $\mathbf{L}^{11} \mathbf{H}_{2}$ would also be a very interesting ligand geometry to explore, since it exhibits the most favorable combination of conformational metrics explored in this study, yet has a great deal of ligand flexibility approaching that of the linear nLi-Me-3,2-HOPO ligands. One final linker of interest for thermodynamic evaluation and selectivity measurements is the 1,8-fluorene linker in $\mathbf{L}^{\mathbf{1 2}} \mathbf{H}_{\mathbf{2}}$, whose uranyl complex displayed very favorable conformational values and whose free ligand structure exhibits a measure of pre-organization for uranyl chelation. $\mathbf{L}^{12} \mathbf{H}_{\mathbf{2}}$ may, however, raise problems in solubility, as its uranyl complex was insoluble in most solvents at exceedingly low concentrations.

Ligands with the $o$-toluene, $m$-toluene, and $o$-xylene linker geometries displayed geometric and/or ${ }^{1} \mathrm{H}$ NMR evidence that their uranyl complexes were not as promising as those with $n=2$ or $n=5$, in that they either exhibited warped coordination geometries, or their intramolecular hydrogen bonding was observed to be relatively poor. Thus, these ligands are not promising for future development.

How the rigidity and geometry of the linkers used affects the selectivity/affinity of bis-Me-3,2HOPO ligands compared to nLi-Me-3,2-HOPO ligands must be addressed by solution phase measurements because of the invariance of the equatorial $\mathrm{U}-\mathrm{O}_{\mathrm{HOPO}}$ bonds observed in this study. Thus, thermodynamic measurements to evaluate the relative affinity of bis-Me-3,2-HOPO ligands that passed this structural screening will be the next step in our pursuit of uranyl ligand optimization.

Acknowledgement. We would like to thank Dr. Fred Hollander at the University of California, Berkeley, and Dr. Simon Teat at the Advanced Light Source, Station 11.3.1 at Lawrence Berkeley National Laboratory for assistance with crystal structure collection and refinement. We also thank Dr. 
David Shuh at LBNL for assistance with handling radioactive materials. This research and the ALS are supported by the Director, Office of Science, Office of Basic Energy Sciences (OBES), and the OBES

Division of Chemical Sciences, Geosciences, and Biosciences of the U.S. Department of Energy at LBNL under Contract No. DE-AC02-05CH11231.

Supporting Information Available: Experimental procedures and description of bis-HOPO ligands, crystallographic information files of new crystal structures, crystallographic refinement details, supplemental crystal structure figures. This material is available free of charge via the Internet at http://pubs.acs.org.

\section{References}

(1) Paper \#61 from the series list "Specific Sequestering Agents for the Actinides." For the previous paper see Szigethy, G.; Raymond, K. N., Inorg. Chem. 2009, 48, 11489-11491.

(2) Greenwood, N. N.; Earnshaw, A. Chemistry of the Elements; Pergamon Press: New York, 1997.

(3) Berthet, J.-C.; Thuery, P.; Dognon, J.-P.; Guillaneux, D.; Ephritikhine, M. Inorg. Chem., 47, 685062.

(4) Maynadié, J.; Berthet, J.-C.; Thuery, P.; Ephritikhine, M. Chem. Comm. 2007, 486-488.

(5) Sarsfield, M. J.; Helliwell, M.; Raftery, J. Inorg. Chem. 2004, 43, 3170-3179.

(6) Copping, R.; Gaunt, A. J.; May, I.; Sharrad, C. A.; Collison, D.; Helliwell, M.; Fox, O. D.; Jones, C. J. Chem. Comm. 2006, 36, 3788-3790.

(7) Nocton, G.; Horeglad, P.; Pécaut, J.; Mazzanati, M. J. Am. Chem. Soc. 2008, 130, 16633-16645.

(8) Yoshida, Z.; Johnson, S. G.; Kimura, T.; Krsul, J. R. In The Chemistry of the Actinide and Transactinide Elements; $3^{\text {rd }}$ ed.; Morss, L. R., Edelstein, N. M., Fuger, J., Eds.; Springer: Dordrecht, The Netherlands, 2006; Vol. 2, p 699-812.

(9) Madic, C.; Begun, G. M.; Hobart, D. E.; Hahn, L. Radiochimica Acta 1983, 34, 195-202.

(10) Arnold, P. L.; Blake, A. J.; Wilson, C.; Love, J. B. Inorg. Chem. 2004, 43, 8206.

(11) Arnold, P. L.; Patel, D.; Blake, A. J.; Wilson, C.; Love, J. B. J. Am. Chem. Soc. 2006, 128, $9610-$ 9611.

(12) Burns, C. J.; Clark, D. L.; Donohoe, R. J.; Duval, P. B.; Scott, B. L.; Tait, C. D. Inorg. Chem. 2000, 3924.

(13) Danis, J. A.; Lin, M. R.; Scott, B. L.; Eichhorn, B. W.; Runde, W. H. Inorg. Chem. 2001, 40, 3389-3394.

(14) Thuéry, P.; Masci, B. J. Chem. Soc. Dalton Trans. 2003, 2411-2417.

(15) Durbin, P. W. Health Phys. 2008, 95, 465-492. 
(16) Grenthe, I.; Drozdzynski, J.; Fujino, T.; Buck, E. C.; Albrecht-Schmitt, T. E.; Wolf, S. F. In The Chemistry of the Actinide and Transactinide Elements; $3^{\text {rd }}$ ed.; Morss, L. R., Edelstein, N. M., Fuger, J., Eds.; Springer: Dordrecht, The Netherlands, 2006; Vol. 1, p 253-698.

(17) Rammo, N. N.; Hamid, K. R.; Ibrahim, T. K. J. Alloys. Compd. 1994, 210, 319-324.

(18) Sarsfield, M. J.; Helliwell, M.; Raftery, J. Inorg. Chem. 2004, 43, 3170-3179.

(19) Templeton, D. H.; Zalkin, A.; Ruben, H.; Templeton, L. K. Acta Cryst. C 1985, C41, 1439-1441.

(20) Franczyk, T. S.; Czerwinski, K. R.; Raymond, K. N. J. Am. Chem. Soc. 1992, 114, 8138-8146.

(21) Walton, P. H.; Raymond, K. N. Inorg. Chim. Acta. 1995, 240, 593-601.

(22) Szigethy, G.; Raymond, K. N. Inorg. Chem. 2009, 48, 11489-91.

(23) Xu, J.; Raymond, K. N. Inorg. Chem. 1999, 38, 308-315.

(24) Casellato, U.; Vigato, P. A.; Tamburini, S.; Graziani, R.; Vidali, M. Inorg. Chim. Acta. 1983, 72, 141-147.

(25) Degetto, S.; Marangoni, G.; Bombieri, G.; Forsellini, E.; Baracoo, L.; Gaziani, R. J. Chem. Soc. Dalton Trans. 1974, 1933-1939.

(26) Drouza, C.; Gramlich, V.; Sigalas, M. P.; Pashalidis, I.; Keramidas, A. D. Inorg. Chem. 2004, 43, 8336-8354.

(27) Garrett, T. M.; Cass, M. E.; Raymond, K. N. J. Coord. Chem. 1992, 25, 241-253.

(28) HostDesigner was developed by B. P. Hay and T. K. Firman at the Pacific Northwest National Laboratory under partial sponsorship of the Chemical Sciences, Office of basic Energy Sciences, Office of Science, U.S. Department of Energy under Contract No. DE-AC06-76RL01830. The software can be obtained at no charge from the following website: http://hostdesigner.emsl.pnl.gov.

(29) Hay, B. P.; Firman, T. K. Inorg. Chem. 2002, 41, 5502-5512.

(30) SAINT: SAX Area-Detector Integration Program, V.6.40; Bruker Analytical X-ray Systems, Inc.: Madison, WI, 2003.

(31) SAINT: SAX Area-Detector Integration Program, V.4.024; Siemens Industrial Automation, Inc, Madison, WI, 1995.

(32) XPREP (V.6.12), Part of SHELXTL Crystal Structure Determination Package; Bruker Analytical X-ray Systems, Inc.: Madison, WI, 2001.

(33) SADABS: Bruker Nonius Area Detector Scaling and Absorption V. 2.05; Bruker Analytical Xray Systems, Inc.: Madison, WI, 2003.

(34) SHELXTL (V.5.10), SHELXTL Crystal Structure Determination Package; Bruker Analytical Xray Systems, Inc.: Madison, WI, 1997.

(35) See Supporting Information for extended pictures of the solid state coordination polymers. 


\section{TOC Synopsis:}

A series of bis[3-hydroxy-N-methyl-pyridin-2-one] ligands was synthesized and their respective uranyl complexes were characterized by single crystal X-ray diffraction. Analysis of these structures reveals that very short (ethyl, 3,4-thiophene and $o$-phenylene) and very long ( $\alpha, \alpha^{\prime}-m$-xylene and 1,8-fluorene) linkers provide optimal ligand geometries about the uranyl cation. ${ }^{1} \mathrm{H}$ NMR analyses indicate that short linkers optimize intramolecular hydrogen bonding that facilitates ligand deprotonation and metal chelation.
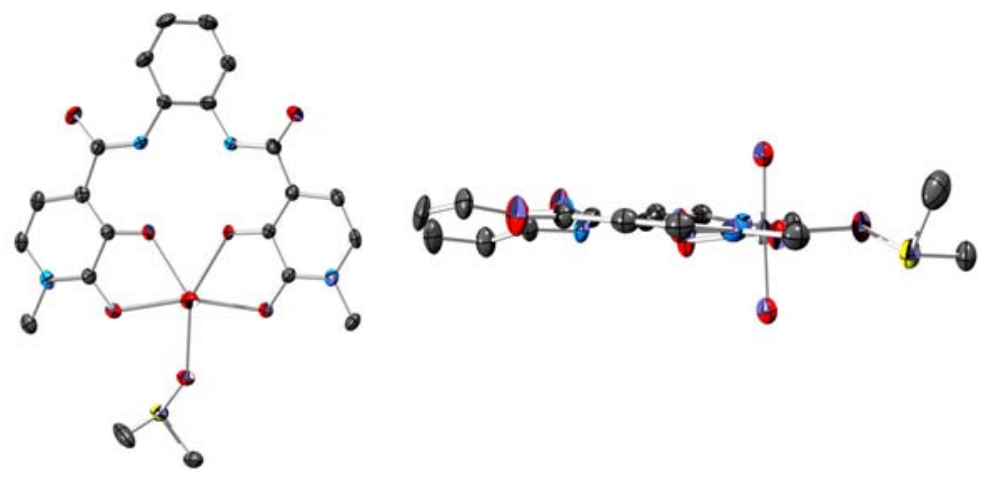